“An Experimental Study of Finitely and Infinitely Repeated Linear Public Goods Games”

\author{
Volodymyr Lugovskyy* \\ Daniela Puzzello* \\ Andrea Sorensen** \\ James Walker* \\ Arlington Williams*
}

*Department of Economics, Indiana University, Bloomington

**Southern Illinois University, Carbondale

Corresponding author: James M. Walker, walkerj@indiana.edu, 812-855-2760

Email Addresses for additional authors:

Volodymyr Lugovskyy (vlugovsk@indiana.edu)

Daniela Puzzello (dpuzzell@indiana.edu)

Andrea Sorensen (sorensen@siu.edu)

Arlington Williams (williama@indiana.edu)

(c) 2017. This manuscript version is made available under the Elsevier user license http://www.elsevier.com/open-access/userlicense/1.0/ 


\title{
“An Experimental Study of Finitely and Infinitely Repeated Linear Public Goods Games"
}

\section{October 11, 2016}

\begin{abstract}
*
A growing literature in experimental economics examines the conditions under which cooperation can be sustained in social-dilemma settings. In particular, several recent studies contrast cooperation levels in games in which the number of decision rounds is probabilistic to games in which the number of decision rounds is finite. We contribute to this literature by contrasting the evolution of cooperation in probabilistically and finitely repeated linear voluntary-contribution public-goods games (VCM). Consistent with past results, ceteris paribus, cooperation is found to increase in the marginal value of the public good. Additionally, as the number of decision sequences increases, there is a pronounced decrease in cooperation in the final round of finite sequences compared to those with a probabilistic end round. We do not, however, find consistent evidence that overall cooperation rates are affected by whether the number of decision rounds is finite or determined probabilistically.
\end{abstract}

Keywords: Social Dilemmas, Public Goods Games, Experimental Economics, Repeated Games.

JEL codes: C72, C92, D83, E40.

\footnotetext{
* The authors are grateful to Ursula Kreitmair for her assistance in conducting these experiments. We also thank David Cooper, Mark Isaac, and other seminar participants for their comments on an early version of this paper presented at Florida State University, as well as reviewers and the editor. Financial support was provided by the National Science Foundation (grant number SES-0849551), the Department of Economics, Indiana University, and the Ostrom Workshop, Indiana University.
} 


\section{Introduction}

The linear voluntary-contribution public-goods game (VCM) has been the cornerstone for examining factors that facilitate cooperation in public-goods settings. The vast majority of this research has focused on the role of game parameters and institutional settings in influencing cooperation. In this regard, much of this research has not focused on VCM settings in which cooperation at the social optimum can be supported as an equilibrium outcome. In particular, most of this research has examined one-shot or finitely repeated decision settings in which the final decision round was common knowledge (see Ledyard (1995) for a review). In our daily lives, however, we also face interactions of uncertain duration. This uncertainty, and the shadow of the future, has the potential to change incentives regarding cooperation relative to situations that are perceived as one-shot or finite in duration. Indeed, repeated interactions may give rise to implicit or explicit punishment schemes that, in turn, may help discipline opportunistic behavior and support cooperation.

The research reported here is motivated by the limited evidence in VCM settings regarding repeated play in the context of uncertain duration. In particular, in a recent study Dal Bó (2005) examines decision making in 2-person prisoner dilemma (PD) games in which subjects participate in sequences of decisions with the same partner and then are re-matched according to a turnpike matching protocol. The experimental design contrasts conditions in which sequences are one shot, repeated with a known end round, or repeated with the end round being determined probabilistically. Our experimental design was motivated by many of the attributes of the methodology used by Dal Bó (2005), but in a VCM game structure with varying number of subjects. The experiment was conducted in several phases, including several treatment conditions motivated by results from earlier phases of the experimental study. In summary, the study began with an investigation of behavior in a VCM game where $\mathrm{N}=4$ and MPCR=0.3 or MPCR $=0.6 .{ }^{1}$ The MPCR=0.3 setting has been shown to lead to low cooperation rates when decision rounds are repeated a publicly announced finite number of times. The MPCR=0.6 setting was chosen based on prior evidence that cooperation levels are higher holding group size constant at $\mathrm{N}=4$ and increasing MPCR (see, Isaac et al., 1994). This result is found to hold although the game-theoretic equilibrium of zero contributions to the public good is the same in both settings when individuals are assumed to make decisions based only on own-income maximization and this is common information. Based on the initial results (contributions were only slightly higher in the settings with a probabilistic end round than those with a known end round), and motivated by the 2-person PD game setting of Dal Bó (2005), we extended our study to include a linear VCM setting with $\mathrm{N}=2$, and MPCR=0.6, with and

\footnotetext{
${ }^{1}$ MPCR is defined as the ratio of the marginal value of contributions to the public good to individual i relative to the opportunity cost to individual i of contributing to the public good.
} 
without limiting subjects to binary choices. In the binary-choice linear VCM games, decisions were either a contribution of zero or a subject's full endowment to the public good.

The experiments reported here follow the methodology of Dal Bó (2005) in the sense that subjects make decisions in the context of repeated sequences of decisions, and groups are fixed within a sequence but not across sequences. The number of decision rounds in a sequence is either finite with a known end round or probabilistic. Thus, in addition to allowing us to contrast the effects of sequences with finite or probabilistic termination rounds, our study also allows us to examine the evolution of contributions in VCM decision settings in which there are a large number of repeated decision sequences and under different parameters. This is especially important since, as in Dal Bó (2005) and Dal Bó and Fréchette (2011), there are multiple equilibria in indefinitely repeated games, and thus it is important to explore parameter changes that may affect cooperation levels.

In summary, we do not find consistent evidence that overall cooperation rates are increased in the experiments with a probabilistic end round compared to finite. We do observe, however, that there is a more pronounced decrease in cooperation in the final round of sequences with a finite end round than in those with a probabilistic end round. In addition, our results for both decision settings support a primary finding related to previous studies examining VCM in finite decision settings that, holding group size constant, contributions increase with increases in MPCR.

The paper is organized as follows. In section 2, we summarize related literature. Section 3 provides a theoretical discussion. Section 4 describes the decision setting, parameters of the games investigated and hypotheses. Section 5 presents the results from the pairs of experiments designed to contrast behavior in the game settings with finite and probabilistic end rounds. Motivated by the results from our initial set of experiments, Section 6 presents the results from an additional set of experiments examining behavior in a setting where the game is presented to subjects in normal form. In addition, we link the results from the experiments to theoretical models that show cooperation can be supported as equilibria in finite settings in PD games, as well as to non-equilibrium models. Section 7 provides a discussion of results and conclusions.

\section{Related Experimental Literature}

Here we discuss laboratory experiments that focus on indefinitely repeated social-dilemma games where the majority of studies explore indefinitely repeated PD games. ${ }^{2}$ Dal Bó (2005) finds that cooperation increases as the probability of continuation increases and that cooperation is higher in games

\footnotetext{
${ }^{2}$ The study of behavior in indefinitely repeated games in laboratory settings goes beyond the PD game and includes (weak or strict) dominance-solvable finite games, oligopoly games, trust games and monetary theory (e.g., Duffy and Puzzello (2014a), Engle-Warnick and Slonim (2006), Holt (1985), Van Huyck, Wildenthal and Battalio (2002)) .
} 
with indefinite duration than in finite games with the same expected length. ${ }^{3}$ In addition, Dal Bó and Fréchette (2011) find that experience plays an important role for the emergence of cooperation in indefinitely repeated PD games. In particular, they find that, with experience, subjects converge to very low levels of cooperation when cooperation is not an equilibrium outcome, while they achieve higher levels of cooperation when both the probability of continuation and the payoff from cooperation are sufficiently high. Blonski et al. (2011) introduce a measure for the riskiness of cooperation for infinitely repeated PD games and show that the sucker's payoff (the payoff a player gets when he cooperates and his opponent defects) plays an important role for cooperation. Duffy and Ochs (2009) explore the effect of matching protocols on the frequency of cooperation in indefinitely repeated PD games and find that the frequency of cooperation is higher when subjects are matched in fixed pairings in comparison to when subjects are randomly paired across games.

There is recent evidence, however, suggesting that in PD games the impact of probabilistic termination rules relative to deterministic end points is not robust to variations in the decision environment. For instance, Norman and Wallace (2012) find that the termination rules do not significantly affect average cooperation rates. Specifically, employing a random termination rule does not cause significantly more cooperation compared to a known finite horizon, and the continuation probability does not significantly affect average cooperation rates. ${ }^{4}$ In addition, Bigoni et al. (2015) explore an experimental setting where subjects played a series of (quasi-) continuous-time PD games. In contrast to earlier studies in discrete-time, they find that cooperation is easier to achieve and sustain with deterministic horizons than with stochastic ones (cooperation can be sustained as an equilibrium in both settings in continuous time). End-game effects are found to emerge, but subjects are found to postpone these effects as they gain experience. The authors show that a simple reinforcement learning model is consistent with observed behavior.

To the best of our knowledge, there are only three papers exploring contributions in indefinitely repeated voluntary-contribution games. Palfrey and Rosenthal (1994) study an indefinitely repeated provision-point voluntary-contribution game, where subjects make a binary choice of whether or not to contribute to the public good. The public good is provided if the number of subjects contributing meets or exceeds a known threshold. In addition, their game setting includes incomplete information as subjects have different (privately known) marginal rates of substitution between the public good and the private good. Unlike the linear voluntary-contribution game, the one-shot version of their game has multiple

\footnotetext{
${ }^{3}$ Roth and Murnighan (1978) and Murnighan and Roth (1983) find mixed evidence for the effect of the probability of continuation on cooperation rates. See Roth (1995) and Dal Bó (2005) for a discussion of methodological weakness of these studies that may have affected the results.

${ }^{4}$ There are important differences between Normann and Wallace (2012)'s study and ours. Their design involves one supergame (our design consists of 15 supergames) and the supergame had a longer horizon.
} 
equilibria with some involving positive contributions. Also, some equilibrium outcomes in the repeated game are associated with higher levels of contribution than equilibrium outcomes of the one-shot games. They find that contributions are higher in the indefinitely repeated game than in the one-shot games, but the differences are small. They observe that this result may be due to the structure of the game, which requires overcoming a difficult coordination problem associated with cut-point contribution strategies and private information.

Sell and Wilson (1999) study an indefinitely repeated $n$-person PD version of a public-good game. In particular, in a binary-choice stage game subjects are shown a payoff matrix where payoffs depend on whether they choose to cooperate or defect and on the number of group members who cooperate. ${ }^{5}$ The payoffs, however, cannot be mapped into a linear VCM game. They study the effect of different probabilities of continuation (0.7, 0.8 and 0.95$)$ and the effect of imposing the grim-trigger strategy, finding that higher probabilities of continuation are associated with a higher frequency of cooperation, but only in treatments where subjects are required to play the grim-trigger strategy. Thus, in isolation, a higher expected length of playing the game is not sufficient to induce significantly higher levels of cooperation.

More recently, Tan and Wei (2014) examine cooperation rates in a linear VCM game setting where subjects make decisions across two sequences, finite (10 decision rounds) and indefinitely repeated (0.9 probability of continuation). They find that average contributions do not differ between the finitely repeated and indefinitely repeated games. However, while contributions decrease in finitely repeated games, they are found to exhibit cycles in indefinitely repeated games. In addition, they find evidence of a restart effect at the beginning of the second sequence only in finitely repeated games.

Relative to Dal Bó (2005) and Dal Bó and Fréchette (2011), our $N=2$ treatment where choices are not binary consists of a somewhat more complex decision environment since subjects have more than two choices available, and thus more degrees of cooperation are possible at the individual level. This aspect of our design led us to conduct an additional treatment condition in which subjects were limited to the binary choices of full contribution or no contribution to the public good. Relative to Tan and Wei (2014), in addition to the effect of changing group size and MPCR, we also explore the impact of experience on the selection of equilibria. That is, in both our known end-round and probabilistic end-round decision environments, subjects participate in a large number of decision sequences, which allows us to more completely explore whether experience plays a role in the selection of equilibria and the evolution of cooperation. There are multiple equilibria in the probabilistic end-round environment, including zero contributions and up to full cooperation. Thus our design allows us to examine to what extent equilibrium selection is affected by game parameters within the context of the linear VCM game, as well as the role of

\footnotetext{
${ }^{5}$ Their parameterization also implies higher returns from cooperation than in our study. For example, the fraction of the social optimum that is achieved under the Nash equilibrium is 0.3 , while in our study that fraction is 0.8333 (when the MPCR is 0.3 ) or 0.416 (when the MPCR is 0.6).
} 
experience. ${ }^{6}$ As in Tan and Wei (2014), we do not find consistent evidence that contribution levels are higher in indefinitely repeated games than in finitely repeated games. Unlike Tan and Wei (2014), we find that restart effects are present in indefinitely repeated games, but they are smaller than in finitely repeated games. $^{7}$

\section{Theoretical Predictions}

In this section we show that it is possible to support full cooperation as a subgame-perfect equilibrium in infinitely repeated voluntary-contribution public-goods games. We start by describing the stage game. Let $N$ be the number of agents in the group. Each agent $i$ is endowed with $Z$ tokens. We denote the action set of agent $i$ by $A_{i}=\{0,1, \ldots, Z\}$, i.e., an agent decides how many tokens, $m_{i} \in A_{i}$ to contribute to a group account, and keeps the rest of his endowment in a private account, with a per token payoff equal to 1. Let $c \in R$ be such that $\frac{1}{N}<\frac{c}{N}<1$. Agent $i$ 's payoff in tokens is determined as follows:

$$
\Pi_{i}\left(m_{1}, m_{2}, \ldots, m_{N}\right)=Z-m_{i}+c \frac{\left(m_{i}+\sum_{j \neq i} m_{j}\right)}{N} .
$$

That is, the total amount contributed to the group account is multiplied by a factor $c>1$, and then divided equally among the group members. In this context where the return from the private account is 1 , the term $\frac{c}{N}$ is the Marginal Per Capita Return (MPCR) from the group account and the restriction $\frac{1}{N}<\frac{c}{N}<1$ implies that this game is a social dilemma. That is, assuming own-income maximization across all players and that this is common knowledge, because $\frac{c}{N}<1$, not contributing to the group account is a strictly dominant strategy in the stage game. However, because $\frac{c}{N}>\frac{1}{N}$, the social optimum is for every agent to contribute their full endowment of tokens to the group account. Thus, the unique Nash equilibrium for this stage game is $\left(m_{1}, m_{2}, \ldots, m_{N}\right)=(0,0, \ldots, 0)$, which is not Pareto optimal. Furthermore, backward induction implies that contributing zero in each period is also the unique subgame-perfect equilibrium of the finitely repeated game.

\footnotetext{
${ }^{6}$ As in Dal Bó and Fréchette (2011), we also randomly re-match subjects across sequences, to limit the extent of repeated-game effects across sequences.

${ }^{7}$ Unlike in Tan and Wei (2014), where subjects were not informed that there could be multiple sequences, the instructions in our experiments explicitly inform the subjects that there will be multiple sequences.
} 
The game with a probabilistically determined ending can be viewed as an infinite repetition of the stage game. As agents interact repeatedly over time, they can now condition their actions in each period on their group members' past actions. Clearly, not to contribute in every period remains a subgameperfect Nash-equilibrium outcome of the infinitely repeated game. Suppose now that the total group endowment, $N Z=K$, is common knowledge. Then, cooperative outcomes, associated with positive contributions to the group account, can be supported as subgame-perfect Nash equilibria of the repeated game. In particular, it is possible to show that, if agents are sufficiently patient, full cooperation (i.e., to contribute all tokens to the group account) can be supported as a subgame-perfect Nash-equilibrium outcome in the infinitely repeated voluntary-contribution public-goods provision game.

Let $t=1,2, \ldots$ denote the time period and $\delta<1$ the discount factor. Payoffs in the infinitely repeated game are determined by the discounted sum of stage payoffs. Recall that the total sum of individual endowments is common knowledge and equal to $K$. Now consider the following grim-trigger strategy:

"Start by contributing all of your tokens to the group account. Contribute all of your tokens to the group account as long as you observe that the total contribution to the group account is equal to $K$. If you observe that the total contribution is less than $K$, contribute 0 to the group account forever after. ",

This strategy prescribes agents to begin playing cooperatively and to continue doing so until a defection is observed. As soon as a defection is observed, the grim strategy prescribes that no one should contribute to the group account forever after, which can be interpreted as "punishment" of the defector in retaliation for his deviation.

Next we show that if agents are sufficiently patient (and thus they care enough about future payoffs), this strategy is a subgame-perfect Nash equilibrium of the infinitely repeated public-goods game. Note also that the equilibrium outcome associated with this strategy is full cooperation and it is supported by the threat of completely shutting down any contribution to the group account. To prove that this strategy is a subgame-perfect Nash equilibrium, we need to show that no agent has an incentive to deviate on and off the equilibrium path.

On the equilibrium path, if agent $i$ follows the strategy, his payoff is given by:

\footnotetext{
${ }^{8}$ Further, we notice that the grim-trigger strategy can support less than full cooperation as a subgame-perfect equilibrium and that there are other strategies that support full cooperation. Also, note that the threshold discount factor does not depend on the level of positive contributions specified by the grim-trigger strategy.
} 


$$
\frac{1}{1-\delta}\left(\frac{c}{N} \sum_{j=1}^{N} Z\right)
$$

While if he deviates, he receives a one-shot gain followed by lower future payoffs:

$$
\left(Z+\frac{c}{N} \sum_{j \neq i} Z\right)+\frac{\delta}{1-\delta} Z
$$

Thus, an agent has no incentive to deviate on the equilibrium path when

$$
\frac{1}{1-\delta}\left(\frac{c}{N} \sum_{j=1}^{N} Z\right) \geq\left(Z+\frac{c}{N} \sum_{j \neq i} Z\right)+\frac{\delta}{1-\delta} Z
$$

or

$$
\delta \geq \frac{\left(1-\frac{c}{N}\right) Z}{\frac{c}{N} \sum_{j \neq i} Z}=\frac{\left(1-\frac{c}{N}\right)}{\frac{c}{N}(N-1)}=\underline{\delta} .
$$

It is easy to see that off the equilibrium path no agent has the incentive to deviate from the grim-trigger strategy of zero contributions in the current and future periods. The intuition for the sustainability of full cooperation is simple: the threat of punishment that reduces agents' long-term payoffs may be sufficient to deter them from exploiting their short-term advantage, if they care enough about the long term (i.e., if $\delta$ is large enough).

In addition, note that parameter changes that decrease $\underline{\delta}$ imply that cooperation can be supported with agents that are "less patient," as cooperation can be supported with lower discount factors. In particular, we examine three such changes in our study: 1) increases in the MPCR, holding group size $(N)$ constant, 2) decreasing $N$ while holding the group-account return (c) constant, and 3) increasing $N$ while changing $c$ so as to hold the MPCR constant. In summary, whether cooperation is easier or more difficult to support in larger groups depends on how the return to the group account is adjusted in response to a group size increase. These observations will guide our Hypotheses presented in the next section.

\section{Experimental Design, Procedures, and Hypotheses}

\subsection{Design and Procedures}

This study occurred over the time frame, 2014 to 2016, with stages of the experiment being motivated by the results from the previous experiments. Table 1 summarizes the experimental design, except for the additional experiments motivated by our initial design and reported in section 6 . Our experimental sessions consisted of 15 sequences of decision rounds, where after each sequence subjects were randomly 
Table 1. Design Parameters

\begin{tabular}{|c|c|c|c|c|c|c|c|c|c|}
\hline Treatment & $\begin{array}{l}\text { Decision } \\
\text { Setting }\end{array}$ & $\begin{array}{l}\text { Group } \\
\text { Size }\end{array}$ & $\begin{array}{l}\text { Binary } \\
\text { Choice }\end{array}$ & $\begin{array}{l}\text { Group } \\
\text { Account } \\
\text { Return }\end{array}$ & MPCR & $\underline{\delta}$ & $\begin{array}{l}\text { Number } \\
\text { of } \\
\text { Sessions }\end{array}$ & $\begin{array}{c}\text { Subjects } \\
\text { Per } \\
\text { Session }\end{array}$ & $\begin{array}{c}\text { Date } \\
\text { Conducted }\end{array}$ \\
\hline 1 & Finite & 4 & No & $\$ .012$ & .3 & & 3 & $\begin{array}{l}16 \\
16 \\
16\end{array}$ & $\begin{array}{l}02 / 11 / 15 \\
04 / 13 / 16 \\
04 / 13 / 16\end{array}$ \\
\hline 2 & Probabilistic & 4 & No & $\$ .012$ & .3 & .78 & 3 & $\begin{array}{l}16 \\
16 \\
16\end{array}$ & $\begin{array}{l}10 / 15 / 14 \\
04 / 12 / 16 \\
04 / 19 / 16\end{array}$ \\
\hline 3 & Finite & 4 & No & $\$ .024$ & .6 & & 3 & $\begin{array}{l}16 \\
16 \\
16\end{array}$ & $\begin{array}{l}04 / 15 / 15 \\
03 / 29 / 16 \\
03 / 30 / 16\end{array}$ \\
\hline 4 & Probabilistic & 4 & No & $\$ .024$ & .6 & .22 & 3 & $\begin{array}{l}12 \\
16 \\
16\end{array}$ & $\begin{array}{l}04 / 17 / 15 \\
03 / 22 / 16 \\
03 / 29 / 16\end{array}$ \\
\hline 5 & Finite & 2 & No & $\$ .012$ & .6 & & 3 & $\begin{array}{l}14 \\
14 \\
12\end{array}$ & $\begin{array}{l}11 / 19 / 14 \\
01 / 16 / 15 \\
04 / 05 / 16\end{array}$ \\
\hline 6 & Probabilistic & 2 & No & $\$ .012$ & .6 & .67 & 3 & $\begin{array}{l}12 \\
16 \\
12 \\
\end{array}$ & $\begin{array}{l}11 / 05 / 14 \\
11 / 19 / 14 \\
04 / 05 / 16\end{array}$ \\
\hline 7 & Finite & 2 & Yes & $\$ .012$ & .6 & & 3 & $\begin{array}{c}8 \\
16 \\
14\end{array}$ & $\begin{array}{l}01 / 22 / 15 \\
02 / 11 / 15 \\
04 / 12 / 16\end{array}$ \\
\hline 8 & Probabilistic & 2 & Yes & $\$ .012$ & .6 & .67 & 3 & $\begin{array}{l}14 \\
12 \\
16\end{array}$ & $\begin{array}{l}01 / 20 / 15 \\
02 / 13 / 15 \\
04 / 06 / 16\end{array}$ \\
\hline
\end{tabular}

All of the Finite sessions consisted of 15 sequences of 5 rounds each.

All Probabilistic sessions consisted of 15 sequences using one of following sets of sequences:

$(3,4,3,7,5,4,8,13,6,3,11,2,4,2,5),(2,7,1,3,17,5,1,4,4,11,1,5,10,8,3)$,

$(6,6,12,4,2,4,15,1,9,6,2,4,5,7,3)$.

Sequence lengths were chosen using continuation probability $\delta=0.8$. 
regrouped. Each treatment condition consisted of sessions in which the number of decision rounds in a sequence was fixed and publicly known (Finite) and sessions in which the number of decision rounds in a sequence was determined by a random draw with an $80 \%$ chance of continuation (Probabilistic). The expected number of rounds in sequences in Probabilistic sessions equaled the number of rounds in the Finite sessions. As in Dal Bó (2005), this design feature is incorporated to examine whether cooperation may be affected by the "shadow of the future" rather than just sequence length. The experiments were programmed using Z-tree (Fischbacher, 2007). Appendix A contains the instructions for the $\mathrm{N}=4$, MPCR $=0.3$, Finite and Probabilistic settings. ${ }^{9}$ The treatments with $\mathrm{N}=2$ were conducted to move to decision settings that more closely paralleled those of Dal Bó (2005). ${ }^{10}$

The experimental sessions were conducted at Indiana University-Bloomington (U.S.). In each session, 8 to 16 subjects were recruited from a subject database that included undergraduates from a wide range of disciplines. Subjects made decisions sitting at workstations that included side-blinders for privacy. At the beginning of each session, subjects privately read a set of instructions, which were then summarized publicly by a member of the research team. Subjects made all decisions privately. The experimental design is an across-subject design. That is, each subject participated in only one session. ${ }^{11}$

Each decision round was a linear VCM game. In each decision round, each subject was endowed with 25 tokens to be allocated between a private account and a group account. For each token placed in his or her private account a subject received $\$ .01$ in payment. For each token placed in the group account, each group of 4 received $\$ .012$ in sessions with MPCR=0.3 and \$.024 in sessions with MPCR=0.6. Each group of 2 received $\$ .012$ with MPCR=0.6. As is the standard in public-goods experiments, the language used was neutral, the terms "contributions" and "public goods" were not used. For brevity, however, in the discussion of results we will use the term "contributions" when discussing tokens allocated to the group account.

After all subjects had made their decisions in each decision round, they were informed of the aggregate allocations to the group account, as well as their earnings in that round. The sessions in which subjects were limited to a binary decision were conducted exactly as the other sessions, except that each subject was allowed only two choices; all tokens placed in the group account or all tokens placed in their private account. Subjects were informed that across decision sequences they would be randomly grouped

\footnotetext{
${ }^{9}$ Initial pilot experiments with $\mathrm{N}=4$ were conducted in 2013 utilizing the NovaNet system that had been the "workhorse" for a large number of experimental projects. Due to a NovaNet system problem, there were instances in which in a few sequences subjects were mistakenly placed in groups of size 3 and 5, instead of 4 . Due to these system issues, and for greater experimental control, we developed the Z-tree software to conduct the sessions reported here.

${ }^{10}$ Subjects were recruited using ORSEE (Greiner 2003). Subjects were recruited for sessions that could last up to 1.5 hours. Sessions took approximately 1 hour to complete.

${ }^{11}$ In the experiments conducted by Dal Bó (2005), within a session, subjects experienced sequences with different probabilities of continuation in the sessions with an indefinite number of decision rounds and different numbers of decision rounds in the sequences where the number of decision rounds was known.
} 
with other group members, 4 or 2 depending on the relevant research condition. ${ }^{12}$ In Probabilistic sessions, the subjects were informed that "The number of decision rounds in each sequence is determined by a computerized random draw. At the end of each decision round in a sequence, there is an $80 \%$ chance that the sequence of decision rounds will continue and a $20 \%$ chance that the sequence will end." Subjects were not informed of the number of sequences: they were told that "the experiment may consist of numerous sequences". All Probabilistic sessions consisted of 15 sequences using one of three sets of sequences, where the number of rounds in a sequence was determined randomly. The average number of rounds per sequence across the three sets of sequences used were: $5.33(\min 2$, $\max 13), 5.47(\min 1, \max$ 17), 5.73 ( $\min 1, \max 15) .{ }^{13}$ In sessions with a known number of end rounds, subjects were explicitly informed that there would be 15 sequences of 5 rounds each. ${ }^{14}$ The subjects earned an average of $\$ 28.76$, with a maximum of $\$ 45.50$ and a minimum of $\$ 15.50$.

\subsection{Hypotheses}

Based on the game parameters chosen for this study and assuming subjects' choices of contributions to the group account are motivated only by maximizing their own earnings and that this is common information among subjects, positive contribution levels, up to full contribution of endowment, can be supported as equilibrium outcomes in the infinitely repeated games. ${ }^{15}$ Thus, because in infinitely repeated games positive contributions are part of equilibria that Pareto-dominate zero-contribution outcomes, we conjecture that subjects are more likely to contribute positive amounts to the group account in the Probabilistic setting.

12 As discussed in Dal Bó and Fréchette (2011), there is no evidence that this random-matching protocol delivers different results than turnpike protocols. Furthermore, this design choice allows us to run more sequences (repeated games) in a session than turnpike-matching protocols would allow. This is an important advantage for our study, especially given that, in part, we focus on groups of 4 subjects. As a robustness check, however, we ran one session of the $\mathrm{N}=2$, Finite-Binary treatment using a turnpike matching protocol, with 20 subjects, which allowed for 10 sequences. Cooperation rates in the first ten sequences of the sessions with random re-matching $(53.8 \%, 63.1 \%$ and $50.6 \%)$ are comparable to the session using the turnpike matching procedure $(53.8 \%)$.

13 The number of rounds in the sequences of the Probabilistic sessions was determined in advance using a randomnumber generator for each sequence, with replacement. See Table 1. Dal Bó and Fréchette (2011) and EngleWarnick and Slonim (2006) document that different sequence lengths may have an impact on cooperative behavior. This led us to use three sets of sequences. See also Fréchette and Yuksel (2016) and Duffy and Puzzello (2014b) for other studies following a similar approach.

14 The decision to inform the subjects of the number of sequences in the Finite sessions was to reinforce the "finiteness" of the experimental session. We chose 15 sequences based on our prior experience in the NovaNet pilot sessions. This number of sequences allowed us to have a sufficient number of sequences in the Finite sessions to compare to the Probabilistic sessions. As a robustness check, two sessions in the ( $\mathrm{N}=2$, Binary-Finite) treatment were conducted where the number of sequences was not announced. Average cooperation rates in these two sessions $(64.7 \%$ and $42.1 \%)$ are comparable to cooperation rates in the sessions where the number of sequences was announced $(46.2 \%, 63.2 \%$ and $49.3 \%)$.

15 Our parameterization with probability of continuation $\delta=4 / 5$ exceeds $\delta_{0.3}^{4} \approx 0.78, \delta_{0.6}^{4} \approx 0.22$ and $\delta_{0.6}^{2} \approx 0.67$, so that full cooperation can be supported as a subgame-perfect equilibrium of the indefinitely repeated games. 
Hypothesis 1. Contributions in repeated games with sequences that have probabilistic end rounds will be greater than or equal to those in repeated games with sequences that have known end rounds.

Based on the theoretical discussions of Section 3 as related to the computation of $\underline{\delta}$, we present the following hypotheses concerning behavior in sessions with probabilistic end rounds. ${ }^{16}$

Hypothesis 2. In games with probabilistic end rounds, contributions will be higher with MPCR=0.6 than $M P C R=0.3$ for groups with $N=4$.

Hypothesis 3a. In games with probabilistic end rounds with a fixed group account return (c), contributions will be higher with $N=2$ than $N=4$.

Hypothesis 3b. In games with probabilistic end rounds, if the group-account return (c) is adjusted to hold MPCR constant, contributions will be higher in groups with $N=4$ than in groups with $N=2$.

In addition to these hypotheses related to contributions in the sessions with probabilistic end rounds, prior evidence from VCM games with $\mathrm{N}=4$ or greater (Isaac et al., 1994) also suggests that in our sessions with known end rounds, support may be found for Hypotheses 2, 3a and 3b. Thus, our design allows us to examine the robustness of the earlier findings in settings with a large number of repeated decision sequences, with random matching of subjects across sequences, and groups of size $\mathrm{N}=2$.

\section{Results}

In section 5.1, we provide descriptive statistics and graphical representations to allow for an overview of average treatment effects and trends across sequences. Section 5.2 provides statistical analyses designed to formally test the observations from section 5.1. Appendix B contains all tables and figures reported in the text along with a more extensive set of results, including alternative model specifications.

\footnotetext{
16 Note, the continuation probability in our design is above the threshold discount factor implied by the parameterizations we study. The theoretical predictions only have implications for the threshold. However, as discussed in Blonski et al. (2011), several studies in applied theory are based on the interpretation that cooperation is more likely with a lower threshold discount factor. Furthermore, prior experimental evidence suggests that in indefinitely repeated PD games, cooperation rates are positively correlated with the difference between the probability of continuation and the threshold probability of continuation obtained under subgame perfection (see Dal Bó and Fréchette (2014)).
} 


\subsection{Descriptive statistics and trends}

The presentation of results begins with an overview that focuses on contributions. Table 2 presents average contribution levels for each treatment condition, allowing for comparisons of: a) the average of the first round of sequence 1 and the average of the first round pooling across all sequences, $b$ ) the average of the last round of sequence 1 and the average of the last round pooling across all sequences, and c) the average across all rounds of Sequence 1 and the average across all rounds. ${ }^{17}$ Thus, in addition to examining all rounds, we also examine first-round and last-round decisions. As discussed in Dal Bó and Fréchette (2014), an advantage of examining first-round behavior is that the number of rounds in the Probabilistic setting varies due to the probabilistic termination rule, potentially affecting the group contribution dynamics within sequences. Examining last-round behavior allows for a clear contrast between behavior in Finite and Probabilistic settings, since in the last round of Finite settings there is no shadow of the future within a particular sequence.

The data presented in Table 2 reveal no systematic evidence to support Hypotheses 1 that contributions are greater in treatments with Probabilistic end rounds relative to treatments with Finite end rounds. Focusing on the last column of Table 2 (all decision rounds), there is evidence that average contributions are greater in the Probabilistic setting than in the Finite setting with group size N=4. However, for groups of size $\mathrm{N}=2$, there is evidence that average contributions are greater in the Finite setting than in the Probabilistic setting. The data reported for the last round of all sequences also show clear evidence of a decay in the last round of Finite sequences relative to the Probabilisitic sequences.

Focusing on the direction of the differences in average contributions (not statistical signficance), the results do provide preliminary support for Hypotheses 2, 3a and 3b. In the Probabilistic settings, focusing on decisions across all rounds (last column of Table 2) average contributions are found to be higher for $\mathrm{N}=4, \mathrm{MPCR}=0.6$ compared to $\mathrm{N}=4, \mathrm{MPCR}=0.3$ (Hypothesis 2), for $\mathrm{N}=2, \mathrm{MPCR}=0.6$ compared to $\mathrm{N}=4$, MPCR=0.3 (Hypotheses 3a), and for $\mathrm{N}=4, \mathrm{MPCR}=0.6$ compared to $\mathrm{N}=2, \mathrm{MPCR}=0.6$ (Hypothesis $3 \mathrm{~b}$ ). The results related to Hypotheses 2 and 3a are also supported in the Finite setting and provide evidence of the robustness of results reported in Isaac, et al. (1994). In relation to Hypotheses 3b, the results from the Finite setting are somewhat at odds with those found in the Probabilisitc setting. That is, in the Finite setting, there is evidence that holding MPCR constant, $\mathrm{N}=2$ settings lead to slightly greater contributions than the $\mathrm{N}=4$ setting ( $41.1 \%$ vs. $39.4 \%$ ). This is particularly true in the case of the $\mathrm{N}=2$ sessions conducted with a binary decision space. In relation to previous studies examining increases in group size holding MPCR constant in finite settings, Isaac, et al. (1994) find a strong group-size effect when increasing group size with low MPCR, but a weaker effect with high MPCR (all with group size of $\mathrm{N}=4$ or greater). In a

\footnotetext{
${ }^{17}$ Table 2 is constructed with contributions by an individual in each decision round as the unit of observation. Table 2B in Appendix B also provides means of contributions for each experimental session.
} 
Table 2. Average Contributions: Percentage of Maximum Possible

\begin{tabular}{|c|c|c|c|c|c|c|c|}
\hline Treatment & $\begin{array}{c}\text { Decision } \\
\text { Setting }\end{array}$ & $\begin{array}{c}\text { First } \\
\text { Round } \\
\text { Sequence } 1\end{array}$ & $\begin{array}{c}\text { First } \\
\text { Round } \\
\text { All } \\
\text { Sequences }\end{array}$ & $\begin{array}{c}\text { Last } \\
\text { Round } \\
\text { Sequence } 1\end{array}$ & $\begin{array}{c}\text { Last } \\
\text { Round } \\
\text { All } \\
\text { Sequences }\end{array}$ & $\begin{array}{c}\text { All } \\
\text { Rounds } \\
\text { Sequence 1 }\end{array}$ & $\begin{array}{c}\text { All } \\
\text { Rounds } \\
\text { All } \\
\text { Sequences } \\
\end{array}$ \\
\hline & & & & & & & \\
\hline 1 & $\begin{array}{l}\mathrm{N}=4 \text {, Finite } \\
\text { MPCR }=0.3\end{array}$ & 43.7 & 24.9 & 23.4 & 8.0 & 35.9 & 15.0 \\
\hline 2 & $\begin{array}{l}\mathrm{N}=4, \\
\text { Probabilistic } \\
\text { MPCR=0.3 }\end{array}$ & 42.9 & 28.8 & 32.1 & 18.2 & 40.2 & 20.5 \\
\hline 3 & $\begin{array}{l}\mathrm{N}=4 \text {, Finite } \\
\text { MPCR }=0.6\end{array}$ & 52.3 & 44.0 & 44.1 & 31.7 & 48.0 & 39.4 \\
\hline 4 & $\begin{array}{l}\mathrm{N}=4, \\
\text { Probabilistic } \\
\text { MPCR=0.6 }\end{array}$ & 55.1 & 47.7 & 49.5 & 40.3 & 53.0 & 42.9 \\
\hline 5 & $\mathrm{~N}=2$, Finite & 50.1 & 52.4 & 38.8 & 15.7 & 46.7 & 41.1 \\
\hline 6 & $\begin{array}{l}\text { N=2, } \\
\text { Probabilistic } \\
\text { MPCR }=0.6\end{array}$ & 45.8 & 44.3 & 47.5 & 32.6 & 41.8 & 35.0 \\
\hline & & & & & & & \\
\hline 7 & $\begin{array}{l}\text { N=2, Finite } \\
\text { MPCR=0.6, } \\
\text { Binary }\end{array}$ & 57.9 & 76.1 & 36.8 & 20.4 & 50.5 & 54.5 \\
\hline 8 & $\begin{array}{l}\mathrm{N}=2, \\
\text { Probabilistic } \\
\text { MPCR=0.6, } \\
\text { Binary }\end{array}$ & 40.5 & 57.8 & 33.3 & 32.9 & 36.8 & 36.7 \\
\hline
\end{tabular}


recent study, Nosenzo et al. (2015) also find evidence of an increase in contributions in a finitely repeated VCM setting, when group size is decreased from $\mathrm{N}=4$ to $\mathrm{N}=2$, holding MPCR constant. ${ }^{18}$

The averages presented in Table 2 mask differences in time trends that may exist across treatment conditions. To gain insight into such differences, Figure 1 displays average contributions as a percentage of maximum for each treatment condition, pairing the data from Finite and Probabilistic settings. As shown, the path of average contributions across sequences is quite similar in the Finite and Probabilisitic settings for $\mathrm{N}=4$, MPCR=0.3 and MPCR=0.6, with the Probabilistic setting displaying a somewhat higher overall average. Similarly, in the N=2, MPCR $=0.6$ setting, the path of average contributions in the Finite and Probabilistic settings are quite similar with the Finite setting displaying a somewhat higher overall average. The $\mathrm{N}=2, \mathrm{MPCR}=0.6$, Binary setting, however, reveals that the path of average contributions in the Finite setting exceeds that of the Probabilistic setting by a larger margin, particularly in the first 9 sequences.

\subsection{Formal Analysis}

This section turns to formal tests of the differences in individual contribution decisions. The order of presentation begins with tests related to Hypothesis 1 , followed by a presentation of results related to Hypotheses 2, 3a, and 3b. To conduct these tests, the data for each treatment were constructed as a panel, with subjects as the cross-sectional dimension and sequences as the time dimension. Because sequence lengths vary in the Probabilistic setting, for each subject the average contribution was computed across the decision rounds within a sequence, instead of the unit of obervation being an individual contribution in a decision round. For example, for the treatment condition, Finite $\mathrm{N}=4, \mathrm{MPCR}=0.6$, there are 16 subjects per session and 15 observations per subject in a session, for a total of 720 observations. Note that in comparison to Table 2, this procedure yields somewhat different mean contributions in the Probabilistic setting where the unit of observation is individual contribution in a decision round.

To contrast behavior in the Finite and Probabilistic settings, the regression model specification below was conducted for four pairs of treatments, with each pair having identical parameters. Specifically, the paired treatment comparisions are 1 and 2, 3 and 4,5 and 6, 7 and 8 (see Table 2). The regression specification is given by:

$$
\operatorname{Contr}_{S}^{t}=\beta_{F} D_{F, s}^{t}+\beta_{P} D_{P, S}^{t}+\varepsilon_{S}^{t}
$$

\footnotetext{
${ }^{18}$ Goeree, Holt and Laury (2002) examine behavior in a menu game setting of one-shot public good games, where subjects make choices in ten treatments without feedback. While contributions are generally higher in larger groups, they observe slightly higher average contributions in groups of $\mathrm{N}=2$ than $\mathrm{N}=4$ in the treatments where the $\mathrm{MPCR}=0.8$ is the same for all group members.
} 
Figure 1. Average Contributions: Percentage of Maximum Possible

1-2. Group Size=4, MPCR $=0.3$

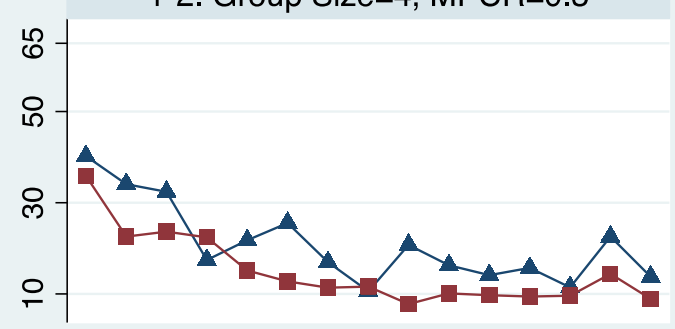

5-6. Group Size=2, MPCR=0.6

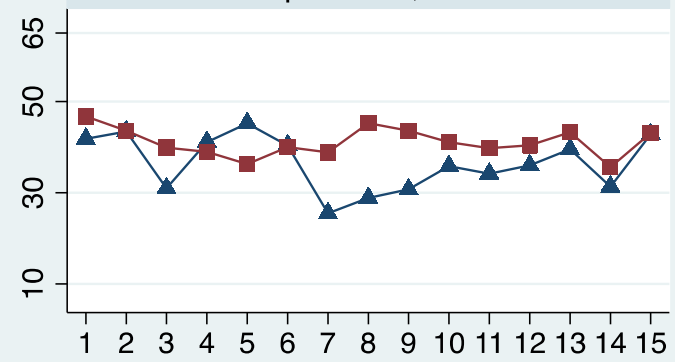

3-4. Group Size=4, MPCR=0.6

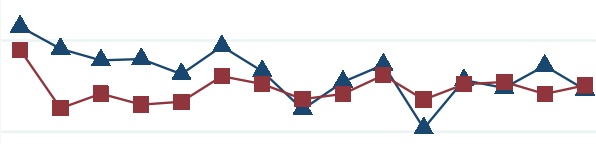

7-8. Group Size=2, MPCR=0.6, Binary

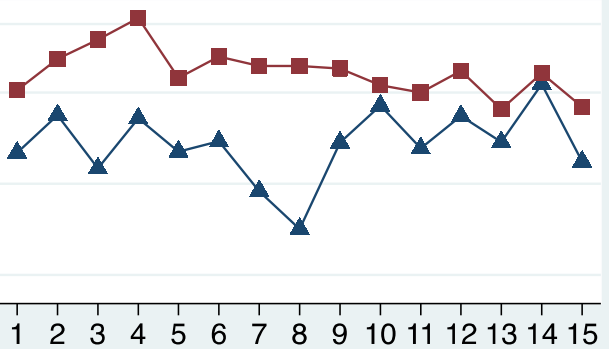
sequence

$$
\text { Probabilistic } \longrightarrow \text { Finite }
$$


where Contr $_{s}^{t}$ is the average contribution of subject $s$ in sequence $t, D_{F}$ and $D_{P}$ are dummy variables for the Finite and Probabilistic settings, and $\varepsilon_{s}{ }^{t}$ is an error term. Recall that in our experiment, subjects are randomly regrouped in each sequence. As a result, in addition to serial correlation, we can expect spatial (cross-sectional) correlation within a session.

Table 3 reports the results from a model specification where we use cluster-robust standard errors by subject. To examine the robustness of results from this specification, Appendix B presents additional results based on using alternative specifications. ${ }^{19}$ All specifications are examined using data from all decision rounds. In addition, because all Finite sessions have 5 decision rounds, as a further test of robustness, the models are examined excluding all decisison rounds greater than 5 in the Probabilistic setting. Finally, as one can see from Table 3, results are reported using data from all sequences (1-15), as well for the first 5 sequences (1-5) and the last five sequences (11-15). Levels of statistical significance are noted in the tables as: $*=10 \%, * *=5 \%$, and $* * *=1 \%$.

Focusing first on model results from examining data from all periods and all sequences (the first 4 rows of Table 3) we observe that the average contributions are significantly higher in the N=4, MPCR=0.3 Probabilistic setting than in the $\mathrm{N}=4, \mathrm{MPCR}=0.3$ Finite setting ( $22.4 \%$ vs. $15 \%)$. However, we observe that the average contributions are significantly higher in the $\mathrm{N}=2$, Binary Finite setting than in the $\mathrm{N}=2$, Binary Probabilistic setting (54.5\% vs. $41.2 \%$ ). These results are generally robust to whether all decision rounds are used (top panel) or only decision rounds 1-5 (lower panel), as well as the various specifications reported in Appendix B, although the level of statistical significance is affected.

As noted above, we find average contributions are somewhat greater in the $\mathrm{N}=4$, MPCR=0.6 Probabilistic setting than the $\mathrm{N}=4, \mathrm{MPCR}=0.6$ Finite setting. This difference is statistically significant in some model specifications provided in Appendix B. Average contributions are also somewhat greater in the $\mathrm{N}=2, \mathrm{MPCR}=0.6$ (non-binary) Finite setting than the $\mathrm{N}=2, \mathrm{MPCR}=0.6$ (non-binary) Probabilistic setting. This difference, however, is not statistically significant in any of the model specifications in Appendix B.

In order to focus more closely on the dynamics of contribution decisions within and across sequences, Table 4 displays the results from the same model specification as in Table 3, with the exception that treatment comparisons are made on the basis of decisions by rounds (rounds 1, 2, 3, 4, 5, and last rounds). ${ }^{20}$ The primary conclusion that can be drawn from these round-by-round comparisons is the importance that the dynamics play across decision rounds. Focusing on the data that includes all

\footnotetext{
${ }^{19}$ The two other specifications shown in Appendix B are Driscoll and Kraay (1998) standard errors and a specification which uses subject-period as unit of observation with dummy variables for decision rounds 1-4, and cluster-robust standard errors by subject. The latter specification is based on the analysis used in Dal Bó (2005).

20 Table 4B in Appendix B reports versions of Table 4 using the same three model specifications as reported for Table 3B in Appendix B, as well as results from considering the first five and last five sequences.
} 
Table 3. Panel Data Analysis of Individual Contribution Decisions: Model - Subject-sequence as unit of observation, cluster robust standard errors by subject

\begin{tabular}{|c|c|c|c|c|c|c|c|}
\hline \multirow[t]{2}{*}{ Decision Setting } & \multirow[b]{2}{*}{ Sequences } & \multicolumn{2}{|c|}{ Finite } & \multirow{2}{*}{$\begin{array}{c}\text { Sign } \\
\text { Comparison } \\
\text { Cluster } \\
\text { S.E. }\end{array}$} & \multicolumn{2}{|c|}{ Probabilistic } & \multirow[b]{2}{*}{$\mathrm{R}^{2}$} \\
\hline & & $\begin{array}{l}\text { N. } \\
\text { Obs. }\end{array}$ & Mean & & Mean & $\begin{array}{l}\mathrm{N} . \\
\text { Obs. }\end{array}$ & \\
\hline $\mathrm{N}=4, \mathrm{MPCR}=0.3$ & $1-15$ & 720 & 15.0 & $<* *$ & 22.4 & 720 & 0.42 \\
\hline $\mathrm{N}=4, \mathrm{MPCR}=0.6$ & $1-15$ & 720 & 39.4 & $<$ & 44.3 & 660 & 0.66 \\
\hline $\mathrm{N}=2, \mathrm{MPCR}=0.6$ & $1-15$ & 600 & 41.1 & $>$ & 38.3 & 600 & 0.65 \\
\hline $\mathrm{N}=2, \mathrm{MPCR}=0.6$, Binary & $1-15$ & 570 & 54.5 & $>* * *$ & 41.2 & 630 & 0.65 \\
\hline $\mathrm{N}=4, \mathrm{MPCR}=0.3$ & $1-5$ & 240 & 23.9 & $<$ & 30.0 & 240 & 0.56 \\
\hline $\mathrm{N}=4, \mathrm{MPCR}=0.6$ & $1-5$ & 240 & 38.8 & $<*$ & 47.3 & 220 & 0.71 \\
\hline $\mathrm{N}=2, \mathrm{MPCR}=0.6$ & $1-5$ & 200 & 41.1 & $<$ & 42.7 & 200 & 0.69 \\
\hline $\mathrm{N}=2, \mathrm{MPCR}=0.6$, Binary & $1-5$ & 190 & 57.8 & $>* * *$ & 43.0 & 210 & 0.69 \\
\hline $\mathrm{N}=4, \mathrm{MPCR}=0.3$ & $11-15$ & 240 & 10.4 & $<*$ & 17.3 & 240 & 0.31 \\
\hline $\mathrm{N}=4, \mathrm{MPCR}=0.6$ & $11-15$ & 240 & 39.4 & $<$ & 41.5 & 220 & 0.62 \\
\hline $\mathrm{N}=2, \mathrm{MPCR}=0.6$ & $11-15$ & 200 & 40.4 & $>$ & 38.8 & 200 & 0.64 \\
\hline $\mathrm{N}=2, \mathrm{MPCR}=0.6$, Binary & $11-15$ & 190 & 50.4 & $>$ & 43.7 & 210 & 0.62 \\
\hline
\end{tabular}


Table 4. Individual Contribution Decisions: Comparisons by Decision Round, Sequences 1-15 Model: Cluster robust standard errors by subject

\begin{tabular}{|c|c|c|c|c|c|c|c|}
\hline \multirow{2}{*}{ Decision Setting } & \multirow{2}{*}{ Sequences } & \multicolumn{2}{|c|}{ Finite } & \multirow{2}{*}{$\begin{array}{c}\text { Sign } \\
\text { Comparison }\end{array}$} & \multicolumn{2}{|c|}{ Probabilistic } & \multirow[t]{2}{*}{$\mathrm{R}^{2}$} \\
\hline & & N. Obs. & Mean & & Mean & N. Obs. & \\
\hline \multicolumn{8}{|l|}{ Only 1st-round decisions } \\
\hline $\mathrm{N}=4, \mathrm{MPCR}=0.3$ & $1-15$ & 720 & 24.9 & $<$ & 28.8 & 720 & 0.42 \\
\hline $\mathrm{N}=4, \mathrm{MPCR}=0.6$ & $1-15$ & 720 & 44.0 & $<$ & 47.7 & 660 & 0.64 \\
\hline $\mathrm{N}=2, \mathrm{MPCR}=0.6$ & $1-15$ & 600 & 52.4 & $>$ & 44.3 & 600 & 0.65 \\
\hline $\mathrm{N}=2, \mathrm{MPCR}=0.6$, Binary & $1-15$ & 570 & 76.1 & $>* *$ & 57.8 & 630 & 0.68 \\
\hline \multicolumn{8}{|l|}{ Only 2nd-round decisions } \\
\hline $\mathrm{N}=4, \mathrm{MPCR}=0.3$ & $1-15$ & 720 & 18.1 & $<* * *$ & 23.2 & 656 & 0.35 \\
\hline $\mathrm{N}=4, \mathrm{MPCR}=0.6$ & $1-15$ & 720 & 43.3 & $<* *$ & 49.0 & 596 & 0.64 \\
\hline $\mathrm{N}=2, \mathrm{MPCR}=0.6$ & $1-15$ & 600 & 51.8 & $>^{* *}$ & 45.4 & 588 & 0.64 \\
\hline $\mathrm{N}=2, \mathrm{MPCR}=0.6$, Binary & $1-15$ & 570 & 68.4 & $>* * *$ & 42.8 & 614 & 0.58 \\
\hline \multicolumn{8}{|l|}{ Only 3rd-round decisions } \\
\hline $\mathrm{N}=4, \mathrm{MPCR}=0.3$ & $1-15$ & 720 & 13.8 & $<$ & 18.0 & 576 & 0.27 \\
\hline $\mathrm{N}=4, \mathrm{MPCR}=0.6$ & $1-15$ & 720 & 40.4 & $\overline{<}$ & 45.1 & 524 & 0.60 \\
\hline $\mathrm{N}=2, \mathrm{MPCR}=0.6$ & $1-15$ & 600 & 48.6 & $>$ & 39.8 & 508 & 0.57 \\
\hline $\mathrm{N}=2, \mathrm{MPCR}=0.6$, Binary & $1-15$ & 570 & 60.7 & $>* * *$ & 36.2 & 530 & 0.52 \\
\hline \multicolumn{8}{|l|}{ Only 4th-round decisions } \\
\hline $\mathrm{N}=4, \mathrm{MPCR}=0.3$ & $1-15$ & 720 & 10.4 & $<* *$ & 17.8 & 480 & 0.23 \\
\hline $\mathrm{N}=4, \mathrm{MPCR}=0.6$ & $1-15$ & 720 & 37.8 & $<$ & 40.9 & 440 & 0.55 \\
\hline $\mathrm{N}=2, \mathrm{MPCR}=0.6$ & $1-15$ & 600 & 36.8 & $>$ & 33.7 & 412 & 0.45 \\
\hline $\mathrm{N}=2, \mathrm{MPCR}=0.6$, Binary & $1-15$ & 570 & 46.8 & $>* * *$ & 31.9 & 436 & 0.42 \\
\hline \multicolumn{8}{|l|}{ Only 5th-round decisions } \\
\hline $\mathrm{N}=4, \mathrm{MPCR}=0.3$ & $1-15$ & 720 & 8.0 & $<* * *$ & 17.0 & 352 & 0.20 \\
\hline $\mathrm{N}=4, \mathrm{MPCR}=0.6$ & $1-15$ & 720 & 31.7 & $<$ & 39.4 & 324 & 0.49 \\
\hline $\mathrm{N}=2, \mathrm{MPCR}=0.6$ & $1-15$ & 600 & 15.7 & $<* * *$ & 28.4 & 292 & 0.29 \\
\hline $\mathrm{N}=2, \mathrm{MPCR}=0.6$, Binary & $1-15$ & 570 & 20.4 & $\overline{<}$ & 25.8 & 310 & 0.23 \\
\hline \multicolumn{8}{|l|}{ Only last-round decisions } \\
\hline $\mathrm{N}=4, \mathrm{MPCR}=0.3$ & $1-15$ & 720 & 8.0 & $<* * *$ & 18.2 & 720 & 0.25 \\
\hline $\mathrm{N}=4, \mathrm{MPCR}=0.6$ & $1-15$ & 720 & 31.7 & $<* * *$ & 40.3 & 660 & 0.51 \\
\hline $\mathrm{N}=2, \mathrm{MPCR}=0.6$ & $1-15$ & 600 & 15.7 & $<* * *$ & 32.6 & 600 & 0.36 \\
\hline $\mathrm{N}=2, \mathrm{MPCR}=0.6$, Binary & $1-15$ & 570 & 20.4 & $<* * *$ & 32.9 & 630 & 0.28 \\
\hline
\end{tabular}


sequences and beginning in the first round, the only significant difference between the Finite setting and the Probabilistic setting is in the $\mathrm{N}=2$, MPCR $=0.6$, binary setting where average contributions in the Finite setting exceed those in the Probabilistic setting by $18.3 \%$. This difference is higher in the $2^{\text {nd }}$ and $3^{\text {rd }}$ decision rounds, falls in the $4^{\text {th }}$, and changes direction in the $5^{\text {th }}$ decision round where the decay in the Finite setting lowers average contributions to below that in the Probabilistic setting. This is also true if one focuses on contribution decisions in the last round of sequences. In the case of $\mathrm{N}=4, \mathrm{MPCR}=0.3$ and MPCR=0.6, average contributions are lower in the Finite setting than in the Probabilistic setting, but not significant in the first round, with that difference tending to grow across decision rounds, especially in the data from the $5^{\text {th }}$ round and the last round of each sequence.

Figures $2 \mathrm{~A}$ and $2 \mathrm{~B}$ visually complement the formal analysis reported in Table 4, presenting average contribution decisions (as a percentage of maximum) for decision rounds 1-5 across all sequences for each of the treatment conditions. ${ }^{21}$ Focusing first on Figure $2 \mathrm{~A}$, two patterns are quite obvious. In the $\mathrm{N}=4$, $\mathrm{MPCR}=0.3$ treatment conditions, there is a clear decay in contributions within and across sequences. There is also evidence of a restart effect with subjects contributing on average more at the beginning of each sequence compared to the last period of the preceeding sequence. ${ }^{22}$ The $\mathrm{N}=4, \mathrm{MPCR}=0.6$ does not have the same pattern of strong decay across sequences, but does reveal a strong restart effect at the beginning of each sequence. The patterns described above are true for both the Finite and Probabilistic settings, although the decay within and across sequences is somewhat stronger in the Finite setting, when the MPCR=0.3.

Figure $2 \mathrm{~B}$, displaying data for the $\mathrm{N}=2$ treatments, reveals a different dynamic than observed for groups of size N=4. First, comparing the Finite and Probabilistic settings in the case of N=2, MPCR=0.6, the decay in final period contributions within and across sequences, as well as the restart effect, are stronger in the Finite setting. The most striking observation, however, occurs in the comparison of the Finite and Probabilistic settings in the $\mathrm{N}=2, \mathrm{MPCR}=0.6$, Binary treatment. In particular, although, as discussed above, the Finite setting yields a strong decay in the final period, the first two decision rounds within the sequences follow a path where contributions tend to increase relative to those observed in the Probabilistic setting.

Using the same methodology discussed above, we now turn to formal tests regarding Hypotheses 2, 3a, and $3 \mathrm{~b}$ for the Probabilistic settings. Hypothesis 2 states that contribution levels will be higher with

\footnotetext{
${ }^{21}$ In order to make the paired comparisons shown in Figure 2, those sequences in the Probabilistic setting with less than 5 decision rounds were omitted.

${ }^{22}$ Recall that in our design subjects are randomly assigned to new groups in each sequence, which makes the definition of our restart effects somewhat different from the restart effects documented in the previous literature, where the focus was on fixed groups across sequences (see, for example, Andreoni, 1988 and Norton, 2015).
} 
Figure 2. Average Contributions: Percentage of Maximum Possible, Decision Rounds 1-5

A. Group Size: $\mathbf{N}=4$

1. Finite, MPCR $=0.3$

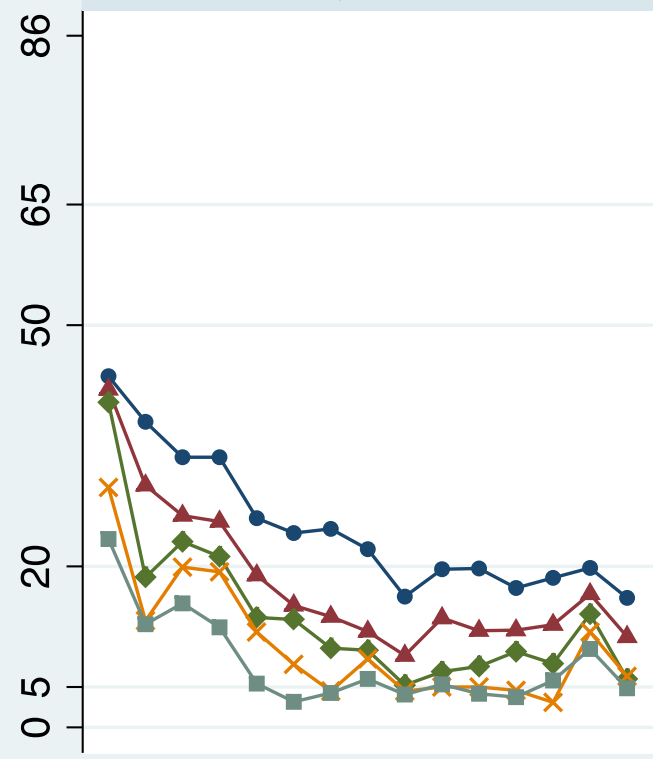

3. Finite, MPCR=0.6

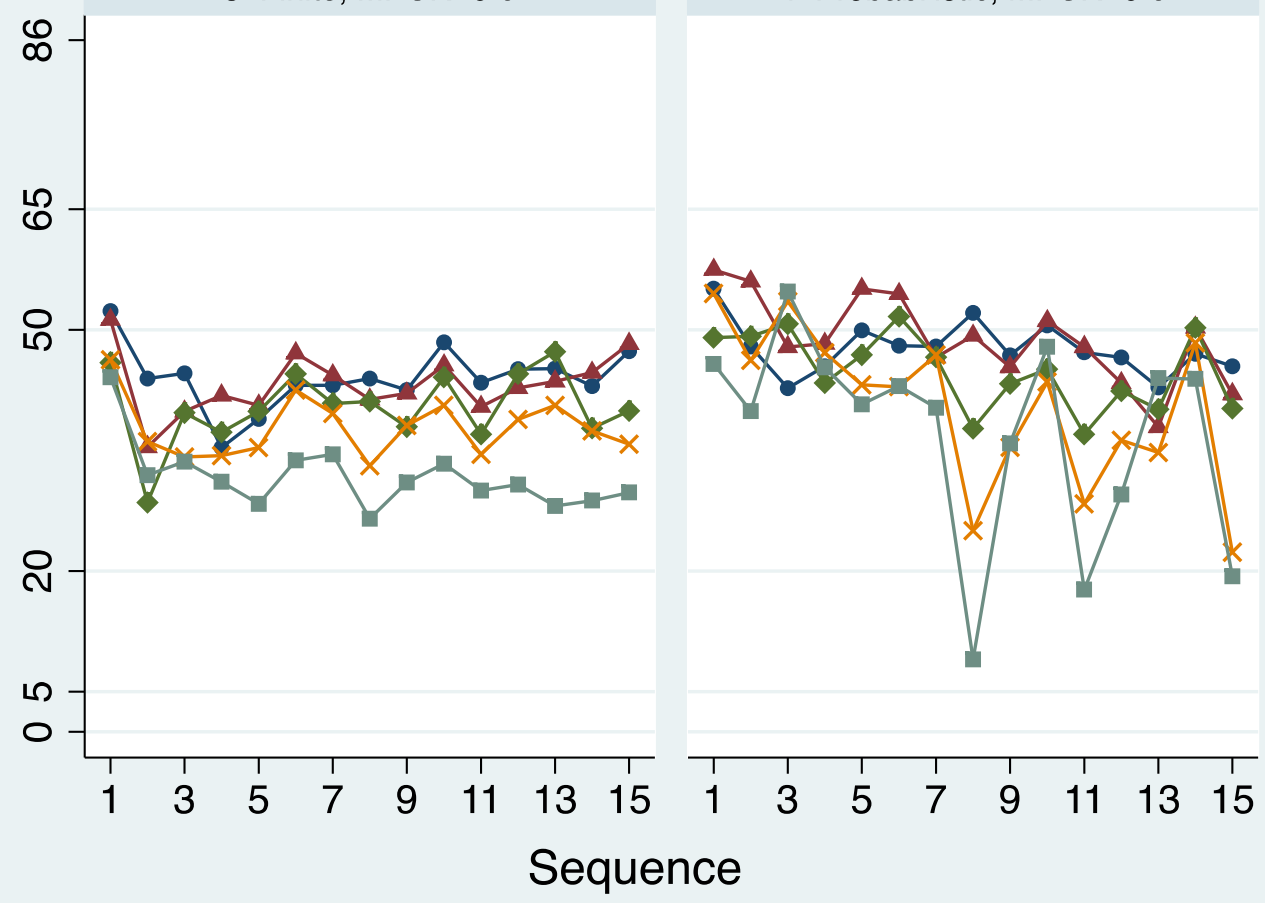

In round $\multimap 1 \multimap 2 \multimap 3 \multimap 4 \longrightarrow 5$ 


\section{B. Group Size: $\mathbf{N}=2$}

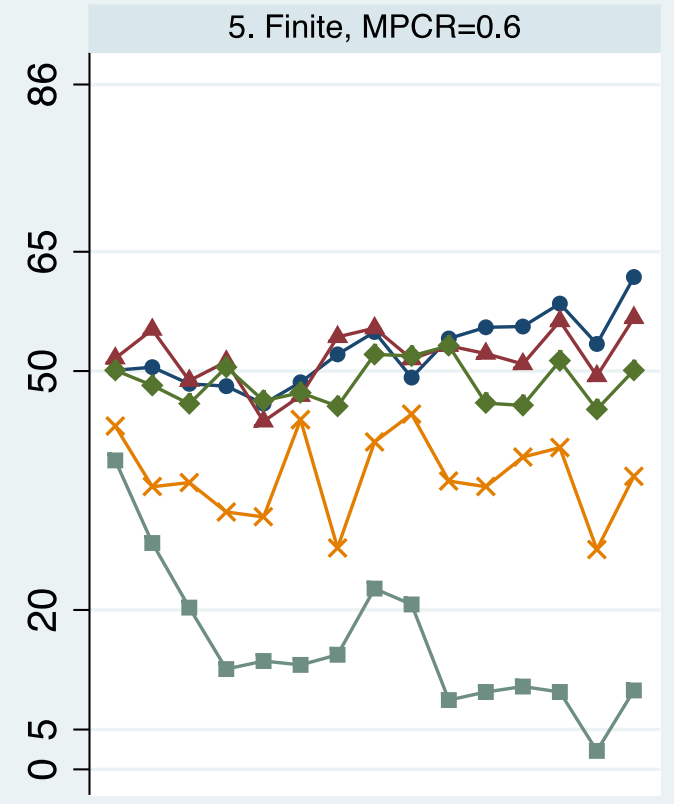

6. Probabilistic, MPCR $=0.6$
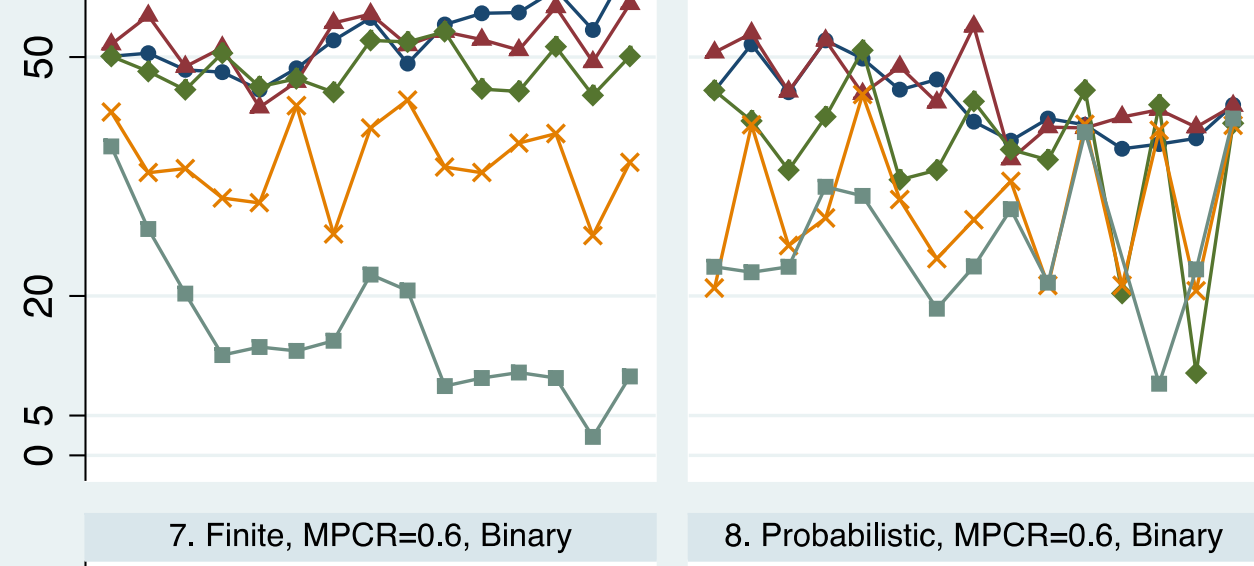

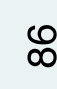

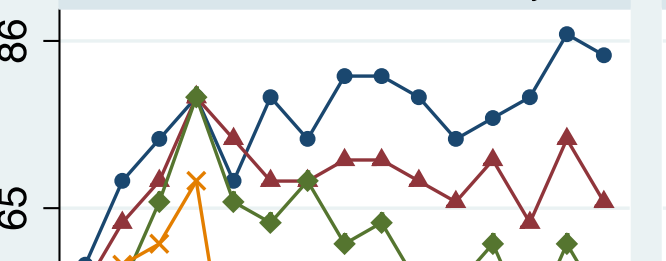

8. Probabilistic, MPCR=0.6, Binary

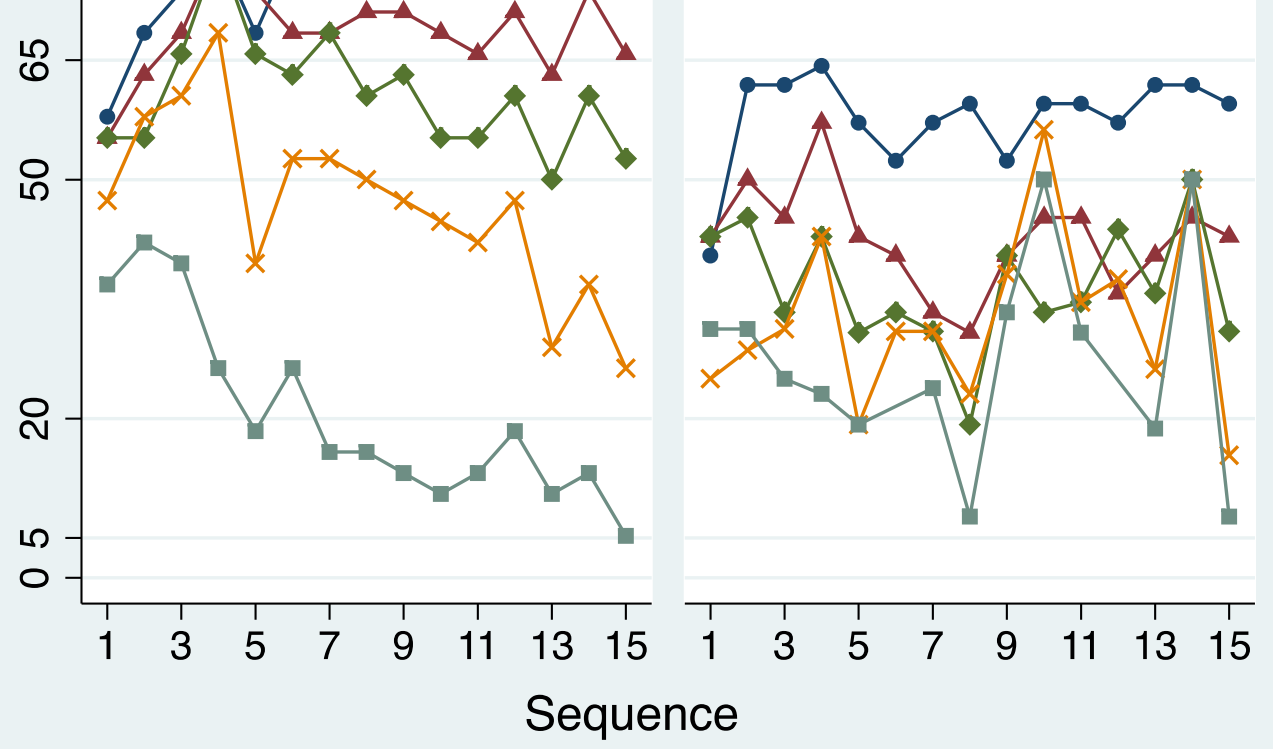

In round $\multimap 1 \longrightarrow 2 \multimap 3 \multimap 4 \longrightarrow 5$ 
$\mathrm{MPCR}=0.6$ than $\mathrm{MPCR}=0.3$ for groups with $\mathrm{N}=4 .^{23}$ Hypothesis 3 a states that, holding the group-account earnings function (c) constant, contributions will be higher with $\mathrm{N}=2$ than $\mathrm{N}=4$. Finally, Hypothesis $3 \mathrm{~b}$ states that, if the group-account return is adjusted to keep the MPCR constant across groups, contributions will be higher in groups with $\mathrm{N}=4$ than in groups with $\mathrm{N}=2$. The model results for all three hypotheses tests are presented in Table 5.

As shown in Table 5, there is strong evidence in support of Hypotheses 2 and 3a. Both hypotheses are also supported when we examine the same treatment comparisons in the relevant Finite settings, consistent with previous findings in the literature. The model results in Table 5 support Hypothesis $3 \mathrm{~b}$ in the sense of the direction of average contributions, but not in terms of statistical significance. That is, holding MPCR constant, in the Probabilistic setting contributions are greater in the $\mathrm{N}=4$ condition compared to the $\mathrm{N}=2$ condition, but the difference is not statistically significant at standard levels. As noted in section 5.1, holding MPCR constant, in the Finite setting we observe contributions to be greater in the $\mathrm{N}=2$ condition compared to the $\mathrm{N}=4$ condition ( $41.1 \%$ vs. $39.4 \%)$. The model results in Table 5 also show this difference to not be statistically significant. ${ }^{24}$ As discussed above, in relation to previous studies examining increases in group size holding MPCR constant, Isaac, et al. (1994) find a strong groupsize effect when increasing group size with low MPCR, but a weaker effect with high MPCR (all with group size of $\mathrm{N}=4$ or greater). Nosenzo et al. (2015) find evidence of a decrease in contributions when group size is increased from $\mathrm{N}=2$ to $\mathrm{N}=4$, holding MPCR constant.

\section{Additional Experiments: VCM vs. PD frame in the Finite Setting}

As discussed in the introduction, the research reported in this study was motivated by the limited evidence in VCM settings regarding repeated play with a probabilistic end round, as well as the recent study of Dal Bó (2005). In the context of PD games, Dal Bó (2005) found that repeated play in settings with uncertain duration leads to significantly higher cooperation levels than repeated play in settings with a known duration. As reported above, investigating decision settings based on the parameters and frame of a VCM game, we did not find consistent evidence of greater contributions in the setting with an uncertain duration. Although we found in the $\mathrm{N}=4, \mathrm{MPCR}=0.3$ parameterization evidence of cooperation in the Probabilistic setting being statistically greater than in the Finite setting, that difference was not of the order of magnitude observed in Dal Bó (2005). Further, we found the opposite result in the $\mathrm{N}=2$, MPCR $=0.6$ binary-choice setting.

${ }^{23}$ Additional tables are provided in Appendix B to examine the robustness of the results reported in Table 5, including two model specifications, as well as results from considering the first five and last five sequences.

24 Both the Probabilistic and the Finite setting differences, however, are statistically significant using the Driscoll-Kraay model specification, when using observations from all sequences. See Table 5C in the supplementary appendix. 
Table 5. Test of Hypotheses 2, 3a, 3b

Data - Include all decision rounds in all sequences

Model - Subject-sequence as unit of observation, cluster robust standard errors by subject

\begin{tabular}{|c|c|c|c|c|c|c|}
\hline \multicolumn{7}{|c|}{ MPCR=0.3 vs MPCR=0.6 with N=4 } \\
\hline \multirow{2}{*}{ Treatment } & \multicolumn{2}{|c|}{$\begin{array}{c}\text { MPCR }=0.3 \\
\mathrm{~N}=4\end{array}$} & \multirow{2}{*}{$\begin{array}{c}\text { Sign } \\
\text { Comparison }\end{array}$} & \multicolumn{2}{c|}{$\begin{array}{c}\text { MPCR=0.6 } \\
\text { N=4 }\end{array}$} & $\mathrm{R}^{2}$ \\
\cline { 2 - 7 } & N. Obs. & Average & Average & N. Obs. & \\
\hline Probabilistic & 720 & 22.4 & $<* * *$ & 44.3 & 660 & 0.62 \\
\hline Finite & 720 & 15.0 & $<* * *$ & 39.4 & 720 & 0.57 \\
\hline
\end{tabular}

\begin{tabular}{|c|c|c|c|c|c|c|}
\hline \multicolumn{7}{|c|}{$\mathbf{N}=\mathbf{4}$ vs N=2, Fixed Group-Account Earnings Function $(\boldsymbol{c})$} \\
\hline \multirow{2}{*}{ Treatment } & \multicolumn{2}{|c|}{$\begin{array}{c}\text { MPCR=0.3 } \\
\text { N=4 }\end{array}$} & \multirow{2}{*}{$\begin{array}{c}\text { Sign } \\
\text { Comparison }\end{array}$} & \multicolumn{2}{c|}{$\begin{array}{c}\text { MPCR }=0.6 \\
\text { N=2 }\end{array}$} & $\mathrm{R}^{2}$ \\
\cline { 5 - 7 } & N. Obs. & Average & & Average & N. Obs. & \\
\hline & & & & & & \\
\hline Probabilistic & 720 & 22.4 & $<* * *$ & 38.3 & 600 & 0.54 \\
\hline Finite & 720 & 15.0 & $<* * *$ & 41.1 & 600 & 0.62 \\
\hline
\end{tabular}

\begin{tabular}{|c|c|c|c|c|c|c|}
\hline \multicolumn{6}{|c|}{$\mathrm{N}=4$ vs $\mathrm{N}=2, \mathrm{MPCR}=0.6$} & \multirow{3}{*}{$\mathrm{R}^{2}$} \\
\hline \multirow[t]{2}{*}{ Treatment } & \multicolumn{2}{|c|}{$\begin{array}{c}\mathrm{MPCR}=0.6 \\
\mathrm{~N}=4\end{array}$} & \multirow{2}{*}{$\begin{array}{c}\text { Sign } \\
\text { Comparison }\end{array}$} & \multicolumn{2}{|c|}{$\begin{array}{c}\mathrm{MPCR}=0.6 \\
\mathrm{~N}=2\end{array}$} & \\
\hline & N. Obs. & Average & & Average & N. Obs. & \\
\hline Probabilistic & 660 & 44.3 & $>$ & 38.3 & 600 & 0.64 \\
\hline Finite & 720 & 39.4 & $<$ & 41.1 & 600 & 0.67 \\
\hline
\end{tabular}


The goal of this study was not to replicate the study conducted in Dal Bó (2005). In fact, there are a number of differences in the game settings, including the game parameters, that may be related to the differences we observe between the two studies. As part of our effort to understand the differences in primary conclusions across the studies, we examined the subset of the data in the Dal Bó (2005) study that is closest to ours. Specifically, we examined the level of cooperation in the ten matches of his probabilistic sessions starting with $\delta=3 / 4$ or finite sessions with 4 decision rounds in his PD2 game. ${ }^{25}$ Importantly, we found that the results of the two studies depart primarily because of differences in cooperation rates in settings with a known end round. More precisely, in the finite setting of Dal Bó (2005), average cooperation rates in the 10 sequences of the PD2 game are $22 \%$, while in the first 10 sequences of our $\mathrm{N}=2$, binary choice treatment they are $56.5 \%$. In his probabilistic setting, however, average cooperation rates in the PD2 game (37.5\%) are quite similar to what we observe in the first 10 sequences of our $\mathrm{N}=2$, binary-choice treatment (35.1\%). These results hold even though normalized cooperation indexes involving the loss from cooperating, the gain from defecting, or the size of the basin of attraction for the two treatment comparisons would predict somewhat lower cooperation rates in our study (see Embrey et al. (2016) for more details on cooperation predictors). ${ }^{26}$

Given the high cooperation rates observed in our Finite $N=2$, binary-choice treatment, it is not necessarily surprising that our Probabilistic setting did not lead to higher contributions than our Finite setting. Further, if one accepts the theoretical explanations provided below for cooperation in repeated games with a known end round, the existence of multiple equilibrium outcomes in the settings with an end round determined probabilistically (including the outcome with zero contributions) no longer implies that outcomes in a probabilistic setting Pareto dominate outcomes in a finite setting. ${ }^{27}$ In other words, the higher are the predicted cooperation rates in a finite setting, the smaller is the set of outcomes in probabilistic settings that Pareto dominate outcomes in the finite setting, except for possibly the last rounds of the finite setting.

To better understand factors that may have led to high cooperation rates in our Finite VCM N=2, Binary setting, we conjectured that the framing of a VCM game relative to a normal form PD game might contribute to higher cooperation rates in the VCM frame. In particular, the VCM game is framed as one in

\footnotetext{
25 We chose to focus on results from PD2 because data from a higher number of sequences (10) was available in comparison to PD1, where there were 7 sequences. The cooperation rates in his PD1 treatment (for the segment of the data closest to ours) are $19.1 \%$ in the finite setting and $36.5 \%$ in the probabilistic setting.

${ }^{26}$ It is worth noting that the cooperation rates in our study are in line with the ones found in Nosenzo et al. (2015) in $\mathrm{VCM}$ games with $\mathrm{N}=2, \mathrm{MPCR}=0.75$, who consider a single sequence (the average contribution in the sequence is $72 \%)$.

${ }^{27}$ For example, Kreps et al. (1982) show that there can be multiple sequential equilibrium outcomes in finite settings. Therefore, a question of equilibrium selection may arise in repeated games with finite end rounds as well as in games with probabilistic end rounds.
} 
which the decision maker allocates an endowment of tokens between a private account and a group account that benefits all group members. The PD game in normal form uses no such language. In fact, the language is especially sparse; outcomes are presented as a result of a single choice made by each player.

Based on these differences in the framing of the decision setting, we conducted three additional experimental Finite sessions (PD) using the parameters of our VCM game N=2, Finite-Binary. The difference between these PD games and the $\mathrm{N}=2$, Binary VCM games is that the games are presented to subjects in normal form as a Prisoner's Dilemma game. Figure 3 and Table 6 contrast the results from the experiments conducted in these two frames. The results are quite striking, with cooperation rates in the PD setting significantly below those in the Binary VCM setting. Indeed, the highest average contribution observed in the PD setting (35.3\%) is lower than the lowest contribution observed in the Binary VCM setting (46.2\%). Figure 4 and Table 7 provide more detailed information related to the dynamics of the decision making across rounds within sequences and across sequences. As shown, the most striking differences between the two sets of experiments occurs in the first few rounds of each sequence, where contributions in the Binary VCM setting are consistently well above those observed in the PD setting. Furthermore, unlike in the PD setting, contributions in the first round tend to be increasing in the Binary VCM setting. Overall, the frame of the game plays a role both for the contribution levels as well as for their dynamics (see also Andreoni (1995) for a study reporting that contributions are higher in positiveframe games than in negative-frame games and Cox and Stoddard (2015) for a review of provision versus appropriation games).

Table 8 reports evidence that is suggestive of how subjects in a VCM game versus a PD game may respond differently to decisions by those with whom they are paired. In particular, focusing on the first 5 sequences of each session, evidence is reported on first-round decisions, as well as how subjects respond to those first-round decisions. Beginning with the first round in the first sequence, the percentage of cooperative choices are almost identical (column A). Columns $\mathrm{C}-\mathrm{H}$, report evidence on decisions in round 2 in response to round 1 . Broadly speaking, the data summarized in these columns are suggestive of a greater willingness in the VCM frame to: a) be more forgiving of a defection by one's partner, and b) follow a strategy of conditional cooperation. For example, a striking observation is the difference in the percentage of subjects that cooperate after observing a defection by their partner (column C): BinaryVCM (50\%), PD (26.7\%). Similarly, the difference in the percentage of round 1 cooperators who also cooperate in round 2 is quite large (column G): Binary-VCM (72.7\%), PD (55.2\%). Additionally, the percentage of round 1 defectors paired with a round 1 cooperator who switched to cooperating in round 2 (column D) is higher in Binary-VCM (30\%) than in PD (20\%). These differences in paths of cooperative behavior tend to be sustained across sequences. By the first round of the fifth sequence, the percentage of cooperative choices in Binary-VCM had increased to $68.4 \%$ and decreased to 50\% in PD. 
Figure 3: Average Group-Account Contributions - Binary VCM vs PD:

Percentage of Maximum Possible

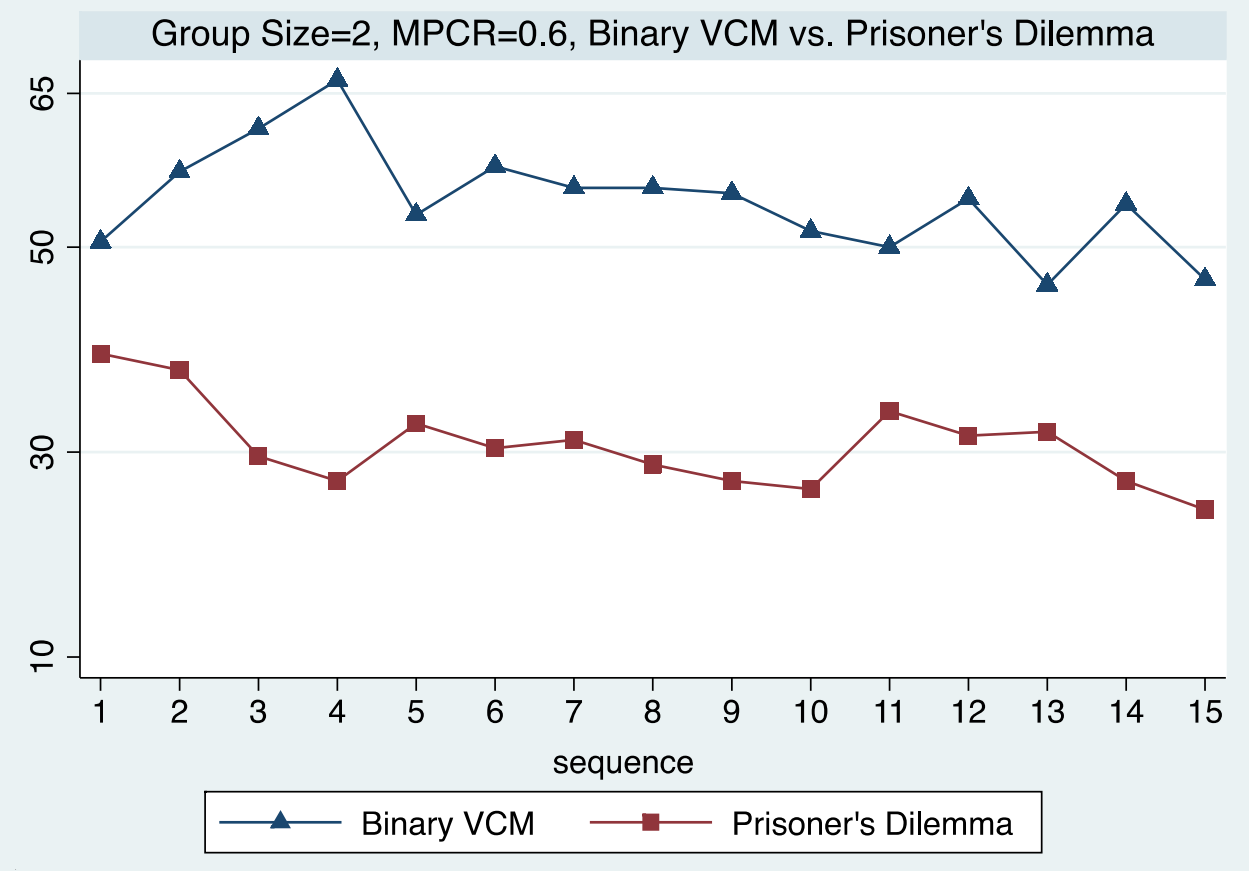

Table 6: Hypothesis Test: $\mathrm{N}=2$ MPCR=0.6 - Binary VCM vs. PD; all rounds

\begin{tabular}{|c|c|c|c|c|c|c|}
\hline \multicolumn{6}{|c|}{ Finite } & \multirow{3}{*}{$\mathrm{R}^{2}$} \\
\hline \multirow[t]{2}{*}{ Sequences } & \multicolumn{2}{|c|}{ Binary VCM } & \multirow{2}{*}{$\begin{array}{c}\text { Sign } \\
\text { Comparison }\end{array}$} & \multicolumn{2}{|c|}{ Prisoner's Dilemma } & \\
\hline & N. Obs. & Average & & Average & N. Obs. & \\
\hline $1-15$ & 570 & 54.5 & $>* * *$ & 30.7 & 750 & 0.64 \\
\hline $1-5$ & 190 & 57.8 & $>* * *$ & 33.4 & 250 & 0.67 \\
\hline $11-15$ & 190 & 50.4 & $>* * *$ & 29.8 & 250 & 0.62 \\
\hline
\end{tabular}


Figure 4: Average Group-Account Contributions: Binary VCM vs PD

Percentage of Maximum Possible: Decision Rounds 1-5

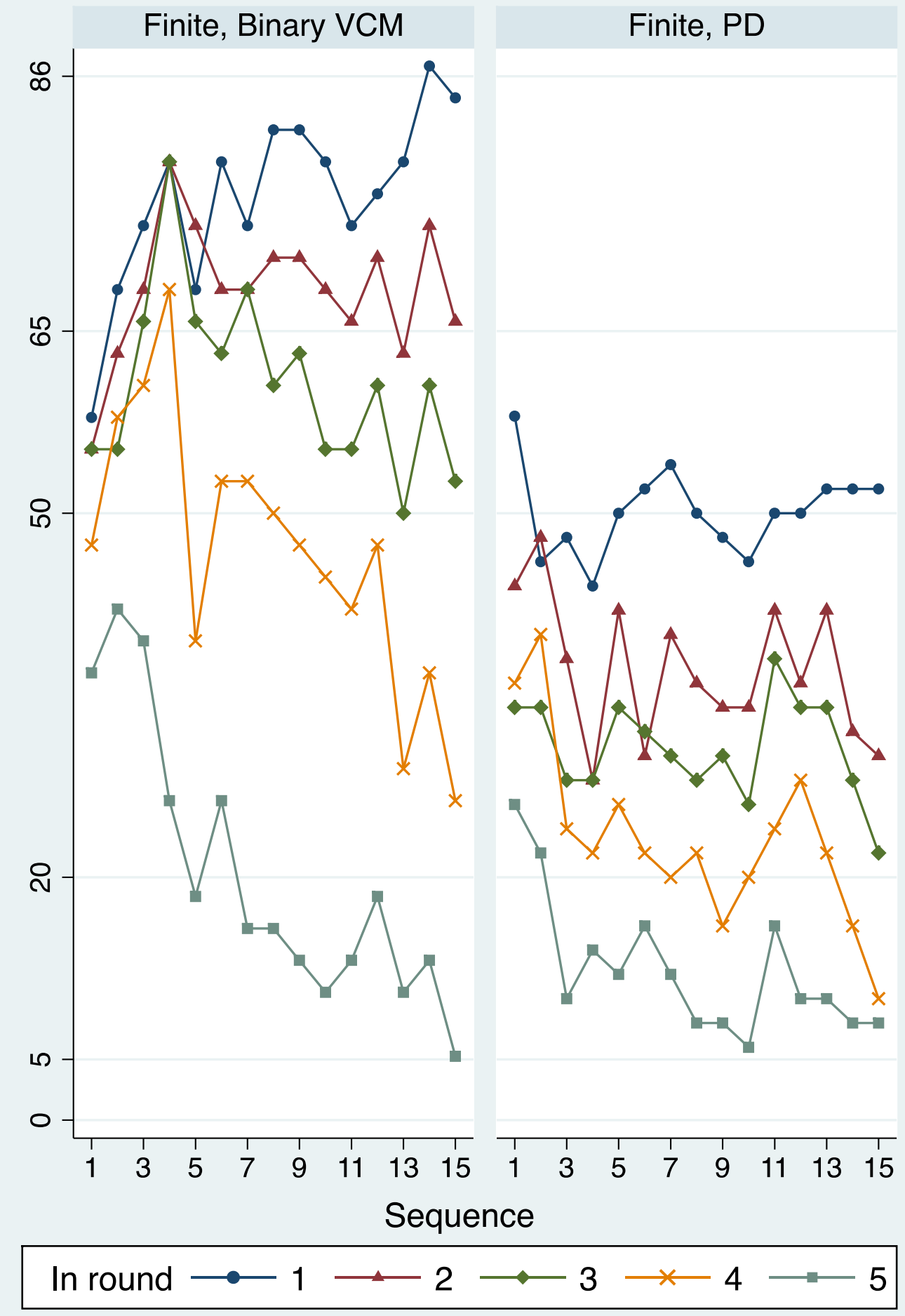


Table 7. Individual Contribution Decisions - Binary VCM vs PD: Comparison by Decision Round Model Specification - Cluster robust standard errors (by subject)

\begin{tabular}{|c|c|c|c|c|c|c|c|}
\hline \multicolumn{8}{|c|}{ Model results using only first-round decisions } \\
\hline \multirow[t]{2}{*}{ Decision Setting } & \multirow{2}{*}{ Sequences } & \multicolumn{2}{|c|}{ Binary VCM } & \multirow{2}{*}{$\begin{array}{c}\text { Sign } \\
\text { Comparison }\end{array}$} & \multicolumn{2}{|c|}{ Prisoner's Dilemma } & $\mathrm{R}^{2}$ \\
\hline & & N. Obs. & Average & & Average & N. Obs. & \\
\hline $\mathrm{N}=2, \mathrm{MPCR}=0.6$ & $1-15$ & 570 & 76.1 & $>* * *$ & 50.1 & 750 & 0.64 \\
\hline $\mathrm{N}=2, \mathrm{MPCR}=0.6$ & $1-5$ & 190 & 69.5 & $>* *$ & 49.2 & 250 & 0.60 \\
\hline $\mathrm{N}=2, \mathrm{MPCR}=0.6$ & $11-15$ & 190 & 80.0 & $>* * *$ & 51.2 & 250 & 0.67 \\
\hline
\end{tabular}

\begin{tabular}{|c|c|c|c|c|c|c|c|}
\hline \multicolumn{8}{|c|}{ Model results using only second-round decisions } \\
\hline \multirow[t]{2}{*}{ Decision Setting } & \multirow{2}{*}{ Sequences } & \multicolumn{2}{|c|}{ Binary VCM } & \multirow{2}{*}{$\begin{array}{c}\text { Sign } \\
\text { Comparison }\end{array}$} & \multicolumn{2}{|c|}{ Prisoner's Dilemma } & $\mathrm{R}^{2}$ \\
\hline & & N. Obs. & Average & & Average & N. Obs. & \\
\hline $\mathrm{N}=2, \mathrm{MPCR}=0.6$ & $1-15$ & 570 & 68.4 & $>* * *$ & 37.1 & 750 & 0.55 \\
\hline $\mathrm{N}=2, \mathrm{MPCR}=0.6$ & $1-5$ & 190 & 67.9 & $>* * *$ & 40.0 & 250 & 0.56 \\
\hline $\mathrm{N}=2, \mathrm{MPCR}=0.6$ & $11-15$ & 190 & 67.9 & $>* * *$ & 36.4 & 250 & 0.55 \\
\hline
\end{tabular}

\begin{tabular}{|c|c|c|c|c|c|c|c|}
\hline \multicolumn{8}{|c|}{ Model results using only third-round decisions } \\
\hline Decision Setting & \multirow{2}{*}{ Sequences } & \multicolumn{2}{|c|}{ Binary VCM } & \multirow{2}{*}{$\begin{array}{c}\text { Sign } \\
\text { Comparison }\end{array}$} & \multicolumn{2}{|c|}{ Prisoner's Dilemma } & $\mathrm{R}^{2}$ \\
\hline & & N. Obs. & Average & & Average & N. Obs. & \\
\hline $\mathrm{N}=2, \mathrm{MPCR}=0.6$ & $1-15$ & 570 & 60.7 & $>* * *$ & 30.7 & 750 & 0.49 \\
\hline $\mathrm{N}=2, \mathrm{MPCR}=0.6$ & $1-5$ & 190 & 64.2 & $>* * *$ & 31.6 & 250 & 0.51 \\
\hline $\mathrm{N}=2, \mathrm{MPCR}=0.6$ & $11-15$ & 190 & 55.8 & $>* * *$ & 31.2 & 250 & 0.45 \\
\hline
\end{tabular}

\begin{tabular}{|c|c|c|c|c|c|c|c|}
\hline \multicolumn{8}{|c|}{ Model results using only fourth-round decisions } \\
\hline \multirow[t]{2}{*}{ Decision Setting } & \multirow{2}{*}{ Sequences } & \multicolumn{2}{|c|}{ Binary VCM } & \multirow{2}{*}{$\begin{array}{c}\text { Sign } \\
\text { Comparison }\end{array}$} & \multicolumn{2}{|c|}{ Prisoner's Dilemma } & $\mathrm{R}^{2}$ \\
\hline & & N. Obs. & Average & & Average & N. Obs. & \\
\hline $\mathrm{N}=2, \mathrm{MPCR}=0.6$ & $1-15$ & 570 & 46.8 & $>* * *$ & 23.2 & 750 & 0.38 \\
\hline $\mathrm{N}=2, \mathrm{MPCR}=0.6$ & $1-5$ & 190 & 54.7 & $>* * *$ & 29.6 & 250 & 0.44 \\
\hline $\mathrm{N}=2, \mathrm{MPCR}=0.6$ & $11-15$ & 190 & 36.3 & $>* * *$ & 20.0 & 250 & 0.29 \\
\hline
\end{tabular}

\begin{tabular}{|c|c|c|c|c|c|c|c|}
\hline \multicolumn{8}{|c|}{ Model results using only fifth-round decisions } \\
\hline \multirow[t]{2}{*}{ Decision Setting } & \multirow{2}{*}{ Sequences } & \multicolumn{2}{|c|}{ Binary VCM } & \multirow{2}{*}{$\begin{array}{c}\text { Sign } \\
\text { Comparison }\end{array}$} & \multicolumn{2}{|c|}{ Prisoner's Dilemma } & $\mathrm{R}^{2}$ \\
\hline & & N. Obs. & Average & & Average & N. Obs. & \\
\hline $\mathrm{N}=2, \mathrm{MPCR}=0.6$ & $1-15$ & 570 & 20.4 & $>^{*}$ & 12.4 & 750 & 0.17 \\
\hline $\mathrm{N}=2, \mathrm{MPCR}=0.6$ & $1-5$ & 190 & 32.6 & $>* * *$ & 16.8 & 250 & 0.26 \\
\hline $\mathrm{N}=2, \mathrm{MPCR}=0.6$ & $11-15$ & 190 & 12.1 & $>$ & 10.4 & 250 & 0.11 \\
\hline
\end{tabular}


Table 8. Path of Choice Combinations by Sequence 1-5: Binary VCM vs PD

\begin{tabular}{|c|c|c|c|c|c|c|c|c|c|}
\hline & & Round $1 \% \mathrm{C}$ & Round $1 \% \mathrm{D}$ & $\begin{array}{l}\% \text { of } \\
\text { R1 C } \\
\text { from } \\
(C, D) \\
\text { also C } \\
\text { in R2 }\end{array}$ & $\begin{array}{l}\text { \% of } \\
\text { R1 D } \\
\text { from } \\
(C, D) \\
\text { switch } \\
\text { to C in } \\
\text { R2 }\end{array}$ & $\begin{array}{l}\% \text { of } \\
\text { R1 C } \\
\text { from } \\
(\mathrm{C}, \mathrm{C}) \\
\text { also C } \\
\text { in R2 }\end{array}$ & $\begin{array}{l}\% \text { of } \\
\text { R1 D } \\
\text { from } \\
(D, D) \\
\text { switch } \\
\text { to C in } \\
\text { R2 }\end{array}$ & $\begin{array}{l}\text { \% of } \\
\mathrm{R} 1 \mathrm{C} \\
\text { also C } \\
\text { in R2 }\end{array}$ & $\begin{array}{l}\% \text { of } \\
\text { R1 D } \\
\text { switch } \\
\text { to C in } \\
\text { R2 }\end{array}$ \\
\hline & & A & B & $\mathrm{C}$ & $\mathrm{D}$ & $E$ & $\mathrm{~F}$ & $\mathrm{G}$ & $\mathrm{H}$ \\
\hline \multirow[b]{2}{*}{$\mathrm{S} 1$} & $\begin{array}{l}\text { Binary } \\
\text { VCM }\end{array}$ & $\begin{array}{c}\mathbf{5 7 . 9} \\
((\mathrm{C}, \mathrm{C})-54.5 \%)\end{array}$ & $\begin{array}{c}\mathbf{4 2 . 1} \\
((\mathrm{D}, \mathrm{D})-37.5 \%)\end{array}$ & 50 & 30 & 91.7 & 33.3 & 72.7 & 31.2 \\
\hline & PD & $\begin{array}{c}\mathbf{5 8 . 0} \\
((\mathrm{C}, \mathrm{C})-48.3 \%) \\
\end{array}$ & $\begin{array}{c}\text { 42.0 } \\
((\mathrm{D}, \mathrm{D})-28.6 \%)\end{array}$ & 26.7 & 20 & 85.7 & 50 & 55.2 & 28.6 \\
\hline \multirow[b]{2}{*}{ S2 } & $\begin{array}{l}\text { Binary } \\
\text { VCM }\end{array}$ & $\begin{array}{c}\mathbf{6 8 . 4} \\
((\mathrm{C}, \mathrm{C})-53.9 \%) \\
\end{array}$ & $\begin{array}{c}\text { 31.6 } \\
((\mathrm{D}, \mathrm{D})-0 \%) \\
\end{array}$ & 50 & 58.3 & 78.6 & NA & 65.4 & 58.3 \\
\hline & PD & $\begin{array}{c}\mathbf{4 6 . 0} \\
((\mathrm{C}, \mathrm{C})-60.9 \%) \\
\end{array}$ & $\begin{array}{c}\mathbf{5 4 . 0} \\
((\mathrm{D}, \mathrm{D})-66.7 \%)\end{array}$ & 44.4 & 22.2 & 100 & 22.2 & 54.5 & 22.2 \\
\hline \multirow[b]{2}{*}{ S3 } & $\begin{array}{l}\text { Binary } \\
\text { VCM }\end{array}$ & $\begin{array}{c}\mathbf{7 3 . 7} \\
((\mathrm{C}, \mathrm{C})-64.3 \%) \\
\end{array}$ & $\begin{array}{c}\mathbf{2 6 . 3} \\
((\mathrm{D}, \mathrm{D})-0 \%) \\
\end{array}$ & 30 & 60 & 94.4 & NA & 71.4 & 60 \\
\hline & PD & $\begin{array}{c}\mathbf{4 8 . 0} \\
((\mathrm{C}, \mathrm{C})-33.3 \%) \\
\end{array}$ & $\begin{array}{c}\mathbf{5 2 . 0} \\
((\mathrm{D}, \mathrm{D})-38.55 \%)\end{array}$ & 25 & 31.2 & 100 & 20 & 50 & 26.9 \\
\hline \multirow[t]{2}{*}{ S4 } & $\begin{array}{l}\text { Binary } \\
\text { VCM }\end{array}$ & $\begin{array}{c}\mathbf{7 9 . 0} \\
((\mathrm{C}, \mathrm{C})-80 \%)\end{array}$ & $\begin{array}{c}\mathbf{2 1 . 0} \\
((\mathrm{D}, \mathrm{D})-25 \%) \\
\end{array}$ & 50 & 66.7 & 95.8 & $\mathbf{0}$ & 86.7 & 50 \\
\hline & PD & $\begin{array}{c}\mathbf{4 4 . 0} \\
((\mathrm{C}, \mathrm{C})-54.6 \%) \\
\end{array}$ & $\begin{array}{c}\mathbf{5 6} \\
((\mathrm{D}, \mathrm{D})-64.3 \%) \\
\end{array}$ & 10 & 10 & 91.7 & 5.6 & 54.6 & 7.1 \\
\hline \multirow[t]{2}{*}{ S5 } & $\begin{array}{l}\text { Binary } \\
\text { VCM }\end{array}$ & $\begin{array}{c}\mathbf{6 8 . 4} \\
((\mathrm{C}, \mathrm{C})-61.5 \%)\end{array}$ & $\begin{array}{c}31.6 \\
((\mathrm{D}, \mathrm{D})-16.7 \%)\end{array}$ & 60 & 60 & 100 & $\mathbf{0}$ & 84.6 & 50 \\
\hline & PD & $\begin{array}{c}\mathbf{5 0} \\
((\mathrm{C}, \mathrm{C})-64 \%) \\
\end{array}$ & $\begin{array}{c}\mathbf{5 0} \\
((\mathrm{D}, \mathrm{D})-64 \%)\end{array}$ & 22.2 & 11.1 & 100 & 12.5 & 72 & 12 \\
\hline
\end{tabular}


There is a long history of theoretical models suggesting that cooperation in finite settings in PD games can be supported (at least in early rounds). In particular, the seminal work of Kreps et al. (1982) argues that cooperation in finitely repeated games can arise due to the presence of incomplete information regarding the true payoffs or the strategy of a rival. In such cases, even rational or self-regarding players may cooperate (except in the last rounds) of a finitely repeated game to gain the payoffs associated with cooperation if those payoffs exceed the short-run gains from defection. ${ }^{28}$ Other studies build on the insights of Kreps et al. (1982). Neyman (1985) shows that cooperation can be supported in finitely repeated prisoner's dilemma games if there is bounded rationality, i.e., when strategies are formalized by finite automata of fixed size implying restrictions on the complexity of strategies players employ. ${ }^{29}$ Radner (1986) shows that cooperation can be part of an epsilon-equilibrium, defined as a pair of strategies such that each player's strategy is very close (within epsilon) to the best response to the opponent's strategy. ${ }^{30}$ Jehiel (2005) also proposes an equilibrium concept, analogy-based expectation equilibrium, ${ }^{31}$ under which it can be part of an equilibrium that players cooperate most of the time except when a deviation has been observed or towards the end of the game (see also Jehiel (2002)).

Complementary to these equilibrium models are models based on error, other-regarding preferences and conditional reciprocity (see discussions in Holt and Laury (2008) and Chaudhuri (2011) in relation to public goods games). Further, Bigoni et al. (2015) provide a reinforcement learning model that is consistent with the evidence that cooperation is higher in deterministic horizon settings than in probabilistic horizon settings in continuous time Prisoner's dilemma games.

Both equilibrium and non-equilibrium approaches suggest that cooperation may be supported in finitely repeated games conditional on path dependencies. ${ }^{32}$ These approaches capture different aspects of behavior and were motivated by data patterns observed in experimental studies. Presumably there are several factors that are simultaneously at play when subjects participate in an experiment, thus it is not surprising that there is no one model consistent with all of the data patterns that have been documented

\footnotetext{
${ }^{28}$ In this approach there may be multiple equilibria and cooperation is not part of every sequential equilibrium.

${ }^{29}$ Zemel (1989) provides an interpretation of Neyman's approach from the perspective of communication, which is introduced to saturate the computational endowment of players.

${ }^{30}$ Radner (1986) also explores other departures from rationality that would help explain cooperation in finite settings: (i) uncertainty about the degree of cooperativeness of the opponent, and (ii) strategies that can be implemented with finite automata with upper bounds on the number of states (as in Neyman (1985)).

${ }^{31}$ According to this equilibrium concept, each player pools nodes at which other players move into analogy classes and forms expectations about the average behavior in each analogy class (rather than forming expectations about behavior at each decision node of each player).

32 See Andreoni, et al. (1993) and Cooper, et al. (1996) for studies explicitly designed to test models of reputation building. Also, Arifovic and Ledyard (2012), Holt and Laury (2008), and Isaac, et al (1994) consider models that could rationalize some of the empirical regularities observed in finitely repeated public-goods experiments including other-regarding preferences and forward-looking behavior (See Chaudhuri (2011) for more references).
} 
(e.g., see Holt and Laury (2008) for a more detailed discussion of this point for public goods games). For example, the approach by Kreps et al. (1982) predicts a decay in cooperation rates (which is consistent with what we observe), but it also predicts that a subject should stop cooperating as soon as his opponent defects. The evidence presented above indicates that this is not what we observe, as subjects are willing to cooperate even after observing a defection, especially in the VCM, N=2, Finite-binary setting. Further, the model by Bigoni et al. (2015) would not be consistent with our evidence since the frequency of cooperators does not increase over sequences in our Finite setting (neither in the VCM, N=2, FiniteBinary setting nor in the PD Finite setting with our parameters).

Finally, we would like to point out that in addition to the frame of the game, parameters (such as the number of rounds, payoffs from cooperation, sucker's payoff, etc.) matter and it is not clear how they interact with factors highlighted in the theoretical explanations mentioned above. Further explorations are needed in order to have a better understanding of factors affecting cooperation in finite games as well as indefinite games (see Embrey et al. (2016), Mengel (2014), Dal Bó and Fréchette (2011), and Norman and Wallace (2012)).

\section{Conclusions and Suggestions for Further Research}

As noted in the introduction to this paper, the linear voluntary-contribution public-goods game (VCM) has been a cornerstone for examining factors that facilitate cooperation in public-goods settings. The previous VCM literature has focused almost entirely on decision making with repeated decision rounds and a known end round. The common finding is that contributions are well above those predicted by the standard model of self-interested actors. The literature has examined the robustness of these findings across parametric changes to the decision setting, in particular group size, marginal value of the public good, and the number of decision rounds. The motivation of this study was to extend this literature into a setting that allows for contrasting the evolution of cooperation in probabilistically and finitely repeated social-dilemma games. The experimental design was motivated by that of Dal Bó (2005), where subjects make decisions in the context of repeated sequences of decisions in PD games, and groups are fixed within a sequence but not across sequences. The number of decision rounds in a sequence is either finite with a known end round or probabilistic.

In summary, across the treatment conditions we examined, we do not find consistent evidence that overall cooperation rates are higher when the number of decision rounds is probabilistic as opposed to when they are finite with a known end round. We do, however, observe a more pronounced decrease in cooperation in the final round of repeated sequences with a commonly known end round compared to those in which the end round is determined probabilistically. Our interpretation of these results is that, in both probabilistic and finitely repeated game settings, the shadow of the future may be a part of the decision process and that the specific parameters of the decision setting remain as important 
explanations for the level of cooperation observed. The additional experiments in the Finite setting that we report in section 6 also suggest that framing the game as a VCM game relative to a normal form PD game may also lead subjects to be more cooperative and patient in the early decision rounds. This latter result is partially consistent with models of finitely repeated games that predict cooperation (at least in early decision rounds) of a finite sequence based on reputation building (e.g. Kreps, et al. 1982), as well as with the public-goods literature that focuses on conditional reciprocity.

In addition to our results contrasting behavior in the Finite and Probabilistic settings, we find support for findings from previous studies examining VCM in finite-decision settings. To our knowledge, this is the first study to examine a VCM setting with a large number of decision sequences, where groups are rematched after each sequence. In both the Probabilistic and Finite settings investigated, we find evidence of a restart effect at the beginning of each decision sequence. Further, holding group size constant, we find evidence that contributions increase with increases in MPCR. We also find weak support in the Probabilistic setting that, holding MPCR constant, contributions increase as group size increases from $\mathrm{N}=2$ to $\mathrm{N}=4$. This result is consistent with the prediction from the model presented in section 3 . However, the latter result is not supported in the Finite setting. Although they did not study groups of size $\mathrm{N}=2$, Isaac et al. (1994) found evidence that, holding MPCR constant, contributions increased (or did not decrease) as group size increased. As mentioned earlier, however, Nosenzo et al. (2015) find evidence of greater contributions with $\mathrm{N}=2$ compared to $\mathrm{N}=4$ in a finitely repeated setting. The combination of these results suggest that future studies examining behavior in the case of $\mathrm{N}=2$ may point to an interesting phenomenon related to public-good provision relative to cases of $\mathrm{N}>2$. In particular, in both the Probabilistic and Finite settings, the $\mathrm{N}=2$ case may facilitate coordination on cooperative strategies.

The evidence suggests that the differences in results across this study and that of Dal Bó (2005) are driven primarily by higher levels of cooperation in our Finite setting relative to that of Dal Bó. This raises the question of what aspects of the two studies might explain this difference. Beyond differences in the framing of VCM and PD games discussed in section 6, there are other differences, in the game settings in the two studies. In particular, the payoff parameters of the games are different, and our horizon of five periods is longer than the longest horizon considered by Dal Bó (2005). Previous studies suggest that the length of the horizon may increase cooperation rates, (e.g., Isaac et al. (1994), Normann and Wallace (2012) and Embrey et al. (2016)). Whether these differences might play a role in the divergence in results of the two studies is a path for future research we plan to follow. In addition, this study and the previous studies discussed above, suggest at least two additional directions for future research involving VCM in both probabilistic and finitely repeated decision settings. The first is gaining a better understanding of the relationship between changes in MPCR, the resulting effect on $\underline{\delta}$, and how subjects respond to these changes. In addition, both Dal Bó (2005) and Isaac et al. (1994) provide evidence that the level of cooperation increases with the number of rounds in the decision sequence. These results suggest that 
examining subjects' responses to systematic changes in the number of decision rounds in repeateddecision sequences may prove fruitful in creating a better understanding of how subjects respond to changes in the shadow of the future. 


\section{References}

Andreoni, James. 1988. "Why Free Ride, Strategies and Learning in Public Goods Experiments," Journal of Public Economics, 37, 291-304.

Andreoni, James. 1995. "Warm-Glow Versus Cold-Prickle: The Effects of Positive and Negative Framing on Cooperation in Experiments," Quarterly Journal of Economics, 110, 1-21.

Andreoni, James and John H. Miller, 1993. "Rational Cooperation in the Finitely Repeated Prisoner's Dilemma: Experimental Evidence." Economic Journal, 103, May 1993, 570-585.

Arifovic, Jasmina and John Ledyard. 2012. "Individual Evolutionary Learning, Other-regarding Preferences, and the Voluntary Contributions Mechanism," Journal of Public Economics 96: 808823.

Blonski, Matthias, Peter Ockenfels and Giancarlo Spagnolo. 2011. "Equilibrium Selection in the Repeated Prisoner's Dilemma: Axiomatic Approach and Experimental Evidence," American Economic Journal: Microeconomics 3: 164-192.

Bigoni, Maria, Marco Casari, Andrzej Skrzypacz, and Giancarlo Spagnolo. 2015. "Time Horizon and Cooperation in Continuous Time," Econometrica Vol. 83, No. 2, 587-616.

Chaudhuri, Ananish. 2011. "Sustaining cooperation in laboratory public goods experiments: a selective survey of the literature," Experimental Economics 14, 47-83.

Cooper, Russell, Douglas DeJong, and Robert Forsythe, 1996. "Cooperation without Reputation: Experimental Evidence from Prisoner's Dilemma Games," Games and Economic Behavior, 12, 187-218.

Cox, Caleb A. and Brock Stoddard (2015) "Framing and Feedback in Social Dilemmas with Partners and Strangers", Games, 6(4), 394-412.

Dal Bó, Pedro. 2005. "Cooperation under the Shadow of the Future: Experimental Evidence from Infinitely Repeated Games," American Economic Review 95: 1591-1604.

Dal Bó, Pedro and Guillaume Fréchette. 2011. "The Evolution of Cooperation in Infinitely Repeated Games: Experimental Evidence," American Economic Review 101: 411-429.

Dal Bó, Pedro and Guillaume Fréchette. 2014. "On the Determinants of Cooperation in Infinitely Repeated Games: A Survey,"mimeo.

Driscoll, John C. and Kraay, Aart C. 1998. "Consistent Covariance Matrix Estimation With Spatially Dependent Panel Data," The Review of Economics and Statistics, MIT Press, vol. 80(4), pages 549-560, November.

Duffy, John and Jack Ochs. 2009. "Cooperative Behavior and the Frequency of Social Interaction," Games and Economic Behavior 66: 785-812.

Duffy, John and Daniela Puzzello. 2014a. "Gift Exchange versus Monetary Exchange: Theory and Evidence," American Economic Review 104: 1735-1776.

Duffy, John and Daniela Puzzello. 2014b. "Experimental Evidence on the Essentiality and Neutrality of Money," Experiments in Macroeconomics (Research in Experimental Economics Volume 17), Bingley, UK: Emerald Group Publishing, 2014, pp. 259-311. Research in Experimental Economics.

Embrey, Matthew, Guillaume Frechette, and Sevgi Yuksel. 2016. "Cooperation in the Finitely Repeated Prisoner's Dilemma," working paper, NYU.

Engle-Warnick, Jim and Robert Slonim. 2006a. "Inferring Repeated-Game Strategies from Actions: Evidence from Trust Games Experiments," Economic Theory 28: 603-632.

Engle-Warnick, Jim and Robert Slonim. 2006b. "Learning to Trust in Indefinitely Repeated Games," Games and Economic Behavior 54: 95-114.

Fischbacher, Urs. 2007. "Z-Tree: Zurich Toolbox for Ready-Made Economic Experiments." Experimental Economics 10 (2): 171-78. 
Fréchette, Guillaume and Sevgi, Yuksel. 2016. "Infinitely Repeated Games in the Laboratory: Four Perspectives on Discouting and Random Termination." Experimental Economics, forthcoming.

Goeree, Jacob, Charles Holt and Susan Laury. 2002. "Private Costs and Public Benefits: Unraveling the Effects of Altruism and Noisy Behavior," Journal of Public Economics 83: 255276.

Greiner, B. 2003. "An Online Recruitment System for Economic Experiments", in Forschung und Wissenschaftliches Rechnen ed. by K. Kremer and V. Macho. GWDG Bericht.

Holt, Charlie. 1985. "An Experimental Test of the Consistent-conjectures Hypothesis," American Economic Review 75: 314-325.

Holt, Charles and Susan Laury. 2008. Theoretical Explanations of Treatment Effects in Voluntary Contributions Experiments, Handbook of Experimental Economics Results Vol.1.

Isaac, Mark, James Walker and Arlington Williams. 1994. "Group Size and the Voluntary Provision of Public Goods," Journal of Public Economics 54: 1-36.

Kreps, David, Paul Milgrom, John Roberts, and Robert Wilson, 1982. "Rational Cooperation in the Finitely Repeated Prisoner's Dilemma,'” Journal of Economic Theory 27, 245-252.

Jehiel, Philippe, 2002. “'Analogy-Based Expectation Equilibrium,'” WP Institute for Advanced Study, Princeton.

Jehiel, Philippe, 2005. “Analogy-Based Expectation Equilibrium,” Journal of Economic Theory 123, 81-104.

Ledyard, John. 1995. Public goods: A survey of experimental research. In: J. Kagel, A. Roth (Eds.), Handbook of Experimental Economics. Princeton: Princeton University Press.

Mengel, Friederike, 2014. "Risk and Temptation: A Meta-Study on Social Dilemma Games," working paper.

Murnighan, Keith and Alvin Roth. 1983. "Expecting Continued Play in Prisoner's Dilemma Games," Journal of Conflict Resolution 27: 279-300.

Neyman, Abraham. 1985. "Bounded Complexity Justifies Cooperation in the Finitely repeated Prisoner's Dilemma," Economics Letters, 19, 227-229.

Nosenzo, Daniele, Simone Quercia, and Martin Sefton. 2015. "Cooperation in small groups: the effect of group size," Experimental Economics, 18, 4-14.

Normann, Hans-Theo and Brian Wallace. 2012. "The impact of the termination rule on cooperation in a prisoner's dilemma experiment," International Journal of Game Theory (2012) 41:707-718.

Norton, Douglas. 2015. "Killing the (coordination) moment: How ambiguity eliminates the restart effect in voluntary contribution mechanism experiments," Economics Letters, Vol. 126, January, Pages 1-5.

Palfrey, Thomas and Howard Rosenthal 1994. "Repeated Play, Cooperation and Coordination: An Experimental Study," Review of Economic Studies 61: 545-565.

Radner, Roy. "Can Bounded Rationality Resolve at the Prisoner's Dilemma?," in Andreu Mas-Colell and Werner Hildebrand, eds., Contributions to mathematical economics.North-Holland, Amsterdam 1986, pp. 387-399.

Roth, Alvin E. "Introduction to Experimental Economics," in John H. Kagel and Alvin E.Roth, eds., The handbook of experimental economics. Princeton: Princeton UniversityPress, 1995, pp. 3-109.

Roth, Alvin and Keith Murnighan. 1978. "Equilibrium Behavior and Repeated Play of the Prisoner's Dilemma," Journal of Mathematical Psychology 17: 189-198.

Sell, Jane and Rick Wilson. 1999. "The Maintenance of Cooperation: Expectations of Future Interaction and the Trigger of Group Punishment," Social Forces 77: 1551-1571.

Tan, Lijia and Lijia Wei. 2014. "Voluntary Contribution Mechanism Played Over an Infinite Horizon," Pacific Economic Review 19: 313-331. 
Van Huyck, John, Wildenthal, John, Battalio, Ray, 2002. "Tacit Cooperation, Strategic Uncertainty, and Coordination Failure: Evidence from Repeated Dominance Solvable Games," Games and Economic Behavior 38: 156-175.

Zemel, Eitan. 1989. "Small Talk and Cooperation: A Note on Bounded Rationality," Journal of Economic Theory 49: 1-9. 